\title{
Investigating the Genetic Structure of Phytophthora capsici Populations
}

\author{
L. M. Quesada-Ocampo, L. L. Granke, M. R. Mercier, J. Olsen, and M. K. Hausbeck
}

Department of Plant Pathology, Michigan State University, East Lansing 48824.

Accepted for publication 7 April 2011.

\begin{abstract}
Quesada-Ocampo, L. M., Granke, L. L., Mercier, M. R., Olsen, J., and Hausbeck, M. K. 2011. Investigating the genetic structure of Phytophthora capsici populations. Phytopathology 101:1061-1073.

Phytophthora capsici Leonian is a destructive soilborne pathogen that infects economically important solanaceous, cucurbitaceous, fabaceous, and other crops in the United States and worldwide. The objective of this study was to investigate the genetic structure of 255 P. capsici isolates assigned to predefined host, geographical, mefenoxam-sensitivity, and mating-type categories. Isolates from six continents, 21 countries, 19 U.S. states, and 26 host species were genotyped for four mitochondrial and six nuclear loci. Bayesian clustering revealed some population structure by host, geographic origin, and mefenoxam sensitivity, with some clusters

occurring more or less frequently in particular categories. Bayesian clustering, split networks, and statistical parsimony genealogies also detected the presence of non- $P$. capsici individuals in our sample corresponding to $P$. tropicalis $(n=9)$ and isolates of a distinct cluster closely related to $P$. capsici and $P$. tropicalis $(n=10)$. Our findings of genetic structuring in $P$. capsici populations highlight the importance of including isolates from all detected clusters that represent the genetic variation in $P$. capsici for development of diagnostic tools, fungicides, and host resistance. The population structure detected will also impact the design and interpretation of association studies in $P$. capsici. This study provides an initial map of global population structure of $P$. capsici but continued genotyping of isolates will be necessary to expand our knowledge of genetic variation in this important plant pathogen.
\end{abstract}

Phytophthora capsici Leonian is a destructive soilborne pathogen that is distributed worldwide. It can infect a broad range of hosts, including economically important solanaceous, cucurbitaceous and fabaceous crops in the United States $(16,21,23,66) . P$. capsici also causes disease on tropical hosts such as cacao (Theobroma cacao), rubber (Hevea brasiliensis), macadamia (Macadamia integrifolia), papaya (Carica papaya), black pepper (Piper nigrum) (11), and rocoto pepper (Capsicum pubescens) (36). Additional hosts continue to be identified $(23,65,66)$. Phytophthora capsici is a diploid oomycete that is heterothallic (11). Hence, sexual reproduction occurs when the A1 and A2 mating types (MTs) come together to produce oospores (43). It is common in vegetable-producing regions in the United States for both MTs to be present $(32,42,69)$. The success of crop rotation as a management strategy is limited by the long-term survival of oospores in the soil (45) and the number and diversity of susceptible hosts (11).

Developing resistant cultivars for economically important hosts has been challenging due to the diversity of pathogen populations and the existence of different physiological races within $P$. capsici in the United States $(56,81)$. A detailed knowledge of the population structure and distribution of genetic variation of $P$. capsici is needed to understand the genetic composition of isolates that occur in particular hosts or regions to develop and intelligently deploy host resistance. Characterizing P. capsici populations for fungicide resistance is also important to establish whether a product will provide effective chemical control against local isolates. Chemical control of $P$. capsici with mefenoxam, a commonly used fungicide, may not protect susceptible crops from

Corresponding author: M. K. Hausbeck; E-mail address: hausbec1@msu.edu

* The $\boldsymbol{e}$-Xtra logo stands for "electronic extra" and indicates that the online version contains three supplementary figures and five supplementary tables.

doi:10.1094/PHYTO-11-10-0325

(C) 2011 The American Phytopathological Society resistant pathogen populations, which have been documented throughout the United States $(42,43,46,59)$.

Populations of $P$. capsici have been previously studied within states in the United States $(18,44,79,82)$ and in countries where this pathogen causes significant losses $(50,73)$. Such investigations have provided information about local genetic diversity of isolates and the importance of recombination in maintaining genetic variability $(43,44)$. Other studies have analyzed $P$. capsici intraspecific data using traditional phylogenetic methods and have established a correlation between phylogenetic cluster and host type, where isolates from woody perennials group together and separate from isolates obtained from vegetable crops $(7,10)$. Previous experiments have also used $P$. capsici intra- and interspecific data to determine whether $P$. capsici and $P$. tropicalis, a sibling species, truly constitute separate species $(7,10,53,88)$ but there is still controversy regarding the evolutionary relationships of these pathogens (7). Studies including worldwide samples to examine the global population structure and distribution of genetic variation in $P$. capsici by geography and host are still lacking.

Most studies of plant pathogen diversity are based on sampling from predefined populations, referred to as "categories" in this article. These categories are usually defined by host, geography, or physiology and may not reflect underlying genetic relationships. Bayesian clustering can be applied to assign individuals in a sample to subpopulations, referred to as "clusters" in this articles, based on their distinct allele frequencies (63). This method has been successfully used to visualize overall patterns of genetic structure in several species $(5,13,14,17,40,71,78)$. Nonetheless, Bayesian clustering has not been as extensively used to detect population structure in plant pathogens and explore the distribution of isolates in different regions or hosts, which may have implications for disease management. In this study, we used Bayesian clustering and other methods to investigate the genetic structure of global $P$. capsici populations. Specifically, we sought to (i) establish whether we could detect population structure in the 
sample; (ii) determine whether the predefined grouping of $P$. capsici isolates in host, geography, mefenoxam-sensitivity, and mating-type categories showed direct correspondence with inferred genetic clusters; and (iii) examine the distribution of isolates belonging to each cluster within the predefined categories.

\section{MATERIALS AND METHODS}

Isolate selection, maintenance, and phenotypic characterization. In total, 255 P. capsici isolates originating from diverse hosts throughout the world were obtained from colleagues or selected from the culture collection maintained in the laboratory of Dr. Hausbeck at Michigan State University (MSU) (Supplementary Table 1). Type cultures for P. capsici 13691 (American Type Culture Collection [ATCC] 64531, Italy 1927) and 13692 (ATCC 15399, New Mexico, deposited 1965) and P. tropicalis 13602 (ATCC 76651, Hawaii 2001) were included in the analysis. Actively growing, single-spore cultures were obtained from longterm stock cultures as previously described (65). Agar plugs from actively growing cultures of each isolate were transferred to $50-\mathrm{ml}$ centrifuge tubes containing $30 \mathrm{ml}$ of unclarified V8 juice broth (UCV8B; $3 \mathrm{~g}$ of $\mathrm{CaCO}_{3}, 160 \mathrm{ml}$ of unfiltered V8 juice, and $840 \mathrm{ml}$ of distilled water), which were maintained at room temperature $\left(21 \pm 2{ }^{\circ} \mathrm{C}\right)$ under constant fluorescent lighting and shaking $(0.03 \times$ $g$ ) to obtain agar-free tissue for DNA extraction. Isolates were characterized according to MT and sensitivity to mefenoxam as previously described (42). The departure of MT ratios from the expected ratio of $1: 1$ (A1:A2) was investigated using a binomial test with exact $P$ values to account for small sample sizes (PROC FREQ, SAS statistical package version 9.1; SAS Institute, Inc., Cary, NC). P. capsici was confirmed using morphological characteristics according to the Phytophthora spp. key by Waterhouse (83).

DNA extraction. Contents of UCV8B centrifuge tubes with actively growing mycelia were vacuum filtered through one layer of Whatman grade 1 filter paper. Tissue remaining on the filter paper was transferred to a mortar using a toothpick and ground with a pestle in liquid nitrogen. All implements were previously sterilized. Genomic DNA was extracted from approximately $1 \mathrm{~g}$ of ground tissue using the DNeasy Plant Minikit (Qiagen, Valencia, CA) according to the manufacturer's instructions. DNA was quantified using the NanoDrop ND 1000 spectrophotometer and NanoDrop 2.4.7c software (NanoDrop Technologies Inc., Wilmington, DE). DNA integrity was analyzed by electrophoresis in $2 \%(\mathrm{wt} / \mathrm{vol})$ agarose gel in $0.5 \times$ Tris-borate-EDTA buffer (52), stained with ethidium bromide $(5 \mu \mathrm{g} / \mathrm{ml})$ for visualization.

Primer design, DNA amplification, and sequencing. Genomic regions to be used as a source of single-nucleotide polymorphism (SNP) markers in $P$. capsici were identified in GenBank (Supplementary Table 2). Selected regions were previously used in oomycete coalescence, genetic diversity, and phylogenetic studies $(6,10,25,58)$. P c capsici sequences from GenBank were input into Primer3 (72) for primer design using default settings. Four regions of the mitochondrial genome (Cox 1, Cox 2, Nad 1, and Nad 5) and six nuclear genes ( $\beta$-tubulin, EF$1 \alpha$, Enolase, HSP90, Tig A, and Ura 3) were amplified by polymerase chain reaction (PCR). PCR was performed in a total volume of $25 \mu \mathrm{l}$ and contained $1 \mu \mathrm{l}$ of 5 -ng/ $\mu \mathrm{l}$ DNA, $5 \mu \mathrm{l}$ of $5 \times$ PCR reaction buffer (Invitrogen, Carlsbad, CA), $1.25 \mu$ of $25 \mu \mathrm{M}$ $\mathrm{MgCl}_{2}$ (Invitrogen), $0.5 \mu \mathrm{l}$ of $10 \mu \mathrm{M}$ dNTP mix (Invitrogen), $1 \mu \mathrm{l}$ of each $10 \mu \mathrm{M}$ primer (MSU Macromolecular Structure Facility, East Lansing), $0.7 \mu \mathrm{l}$ of Platinum Taq DNA polymerase (Invitrogen), and $14.6 \mu \mathrm{l}$ of sterile water. The PCR was performed in a programmable Eppendorf mastercycler ep systems thermal cycler (Eppendorf, Westbury, NY) starting with $3 \mathrm{~min}$ of denaturation at $94^{\circ} \mathrm{C}$; followed by 45 cycles at $94^{\circ} \mathrm{C}$ for $30 \mathrm{~s}$, annealing at $56^{\circ} \mathrm{C}$ for $30 \mathrm{~s}$, and extension at $72^{\circ} \mathrm{C}$ for $60 \mathrm{~s}$; with a final extension step of $10 \mathrm{~min}$ at $72^{\circ} \mathrm{C}$. PCR products were analyzed by electrophoresis in $2 \%$ (wt/vol) agarose gel in $0.5 \times$ Tris-borate-EDTA buffer (52), stained with ethidium bromide $(5 \mu \mathrm{g} / \mathrm{ml})$ for visualization, and compared with a 100-bp ladder (Invitrogen). Controls with no $P$. capsici DNA were included.

PCR products were purified using ExoSAP-IT (Affymetrix, Inc., Santa Clara, CA) following the manufacturer's instructions. Cycle sequencing reactions ( $1 \mu \mathrm{l}$ of purified PCR product, $3 \mu \mathrm{l}$ of primer, and $8 \mu \mathrm{l}$ of sterile water) were done twice directly from the clean PCR products at the MSU Research Technology Support Facility (East Lansing) using the ABI PRISM 3100 Genetic Analyzer (Applied Biosystems, Foster City, CA). A subset of samples with heterozygote positions (40\%) determined from sequence analysis were resolved into haplotypes by cloning the corresponding PCR product using the pGEM-T Easy Vector System (Promega, San Luis Obispo, CA) and Subcloning Efficiency DH5 $\alpha$ Competent Cells (Invitrogen) following the manufacturer's instructions. Cloned PCR products were purified using the QIAquick PCR purification kit (Qiagen) following the manufacturer's instructions, and amplified and sequenced as described above. Obtained haplotypes were confirmed by using PHASE (74) as implemented in DnaSPv5 (49) by running simulations with 5,000 iterations. In all cases, the inferred haplotype with cloning and direct sequencing data matched the haplotypes obtained using PHASE. Haplotypes of remaining samples with heterozygote positions were inferred with PHASE.

Sequence analysis. Manual editing of base calls and sequence alignment were performed using Lasergene SeqMan Pro version 8.0 (DNASTAR Inc., Madison, WI). The alignment was exported as a FASTA file and imported into MacClade (51) to produce a NEXUS file required for subsequent analyses. The two haplotypes within sequences containing heterozygote sites were inferred by haplotype subtraction (25) according to data from direct and cloned PCR product sequencing or by using PHASE as described above. Sequences from mitochondrial and nuclear loci were analyzed individually and collapsed into unique haplotypes using DnaSPv5. Haplotypes found for each gene were deposited in GenBank under accession numbers HQ388837 to HQ389193. Haplotype sequences were compared with sequence data publicly available and sequences from type cultures included in our study by using nucleotide BLAST $(1,2)$ to determine that data corresponded to the $P$. capsici target genes. BLAST analyses indicated that some $P$. capsici isolates corresponded to $P$. tropicalis and to another group of isolates, with some genes showing high similarity to $P$. capsici and others to $P$. tropicalis. These isolates are referred to in this article as intermediate. Two separate data sets were created for subsequent analysis to account for the presence of isolates that did not have high genetic similarity to $P$. capsici in all sequenced genes: $P$. capsici sensu stricto (SS), which included isolates with all gene sequences having high similarity to only $P$. capsici, and $P$. capsici sensu lato (SL), which included all isolates. Base substitutions in SS were classified as phylogenetically informative or uninformative, transitions or transversions, and synonymous or nonsynonymous substitutions using DnaSPv5.

DNA sequence variability, neutrality tests, recombination, and genealogies. Polymorphism, neutrality, and recombination analyses were performed for each gene and all SS isolates using the program DnaSPv5. Polymorphism estimates were also calculated for SS isolates grouped in geographic (hemisphere, continent, country, U.S. state, and United States or not), host (vegetable crop or not, host family, and host species), mefenoxam resistance, and MT categories. Polymorphism analysis was also performed for SL isolates grouped in a species ( $P$. capsici or not) category. Previous work used five individuals as the minimum needed for population analyses in $P$. ramorum (28). We included only categories with at least eight individuals in SS for analyses. Sequence diversity estimates and statistics, including the number of segregating sites (s) and haplotypes (h), haplotype diversity 
(Hd) (54), Tajima's $\pi$ (76), the average number of pairwise nucleotide differences $(\mathrm{k})(76)$, and Watterson's theta $(\theta \mathrm{w})$ per sequence (84), were calculated. Sequence variation in each gene for all SS isolates was tested for deviations from neutrality by using Fu and Li's D and F and Tajima's D $(19,77)$. The recombination parameter (R) per gene (34) and minimum number of recombination events (RM) (35) were also estimated for each gene and all SS isolates. The split network method implemented in SplitsTree v. 4 b06 (37) was used to visualize incompatibilities in SL haplotypes by generating a NeighborNet network based on uncorrected $P$ distances. Network support was assessed by running 10,000 bootstrap replicates. Statistical-parsimony genealogies for haplotypes in SL were generated using TCS v. 1.13 (8).

Population subdivision analysis. Population subdivision was assessed with the model-based Bayesian clustering algorithm implemented in Structure 2.3X (63). The values for burnin, chain replication, and lambda were set at 300,000, 100,000, and 1, respectively, based on results obtained in preliminary analyses. The optimal number of populations $(K)$ was determined by comparing posterior distribution likelihoods among three independent runs of $K=1$ to 40 using the established parameters. Data included all loci individually coded by haplotype and were analyzed under the admixture model with correlated allele frequencies and without previous population information. Population structure figures with prior population information, obtained from the defined geographic, host, mefenoxam-sensitivity, and MT categories for SS and species category for SL and sorted by Q, were generated using the Population Sorting Tool (PST), a graphic editing program created in $\mathrm{R}(67)$ to visualize the distribution of clusters in predefined categories (J. J. Morrice, unpublished data). Genetic differentiation indexes (Wright's $\mathrm{F}_{\mathrm{ST}}$ ) were calculated for SS data grouped by geographic, host, mefenoxamsensitivity, and MT categories and for SL for a species category using DnaSPv5. Statistical significance was determined for each index by running 5,000 permutations $(\alpha=0.05)$.

\section{RESULTS}

Haplotype sequences for each gene were compared with publicly available $P$. capsici sequences in GenBank and sequences from type cultures included in our study through BLAST (data not shown). Nineteen isolates that were not as similar to $P$. capsici as expected were found. Some isolates $(n=9)$ showed higher similarity to $P$. tropicalis than to $P$. capsici across all genes analyzed. Interestingly, other isolates $(n=10)$ showed higher similarity to $P$. tropicalis than $P$. capsici in some genes but had higher similarity to $P$. capsici than to $P$. tropicalis in others (intermediate isolates). $P$. tropicalis and intermediate isolates were included in the SL $(n=255)$ data set and excluded from SS $(n=$ 236) for further analyses.

All genes were polymorphic but nuclear genes were more variable than mitochondrial genes, as indicated by polymorphism analysis (Supplementary Table 3) and diversity estimates (Supplementary Table 4). The total number of segregating sites detected for all SS genes was 120 out of 4,170 bp analyzed. In general, all nuclear genes presented moderate to high values of R and RM. Fu and Li's D and F indicated a significant deviation from neutrality in $\mathrm{Nad} 5$, and $\mathrm{Fu}$ and Li's $\mathrm{D}$ showed a deviation in TigA (Supplementary Table 4). Unique haplotypes occurred in all genes and their frequency range was between $20 \%(\mathrm{Nad} 1)$ and $40 \%$ (TigA) (Supplementary Table 5). Of the 255 isolates, 220 unique multilocus genotypes were detected. Each of the 9 P. tropicalis and 10 intermediate isolates possessed a unique multilocus genotype.

The SS structure analysis detected some population structure by host, geography, and mefenoxam sensitivity, where some clusters occurred more frequently in certain categories than others. However, the analysis showed no direct correspondence between groupings of $P$. capsici isolates in the predefined categories (host, geography, MT, and mefenoxam sensitivity), and inferred genetic clusters. A clear peak in likelihoods in SS was observed when the number of clusters was set to nine $(K=8, \operatorname{lnP}=-6001 ; K=9$, $\ln \mathrm{P}=-5926 ; K=10, \ln \mathrm{P}=-6028)$. Individual ancestry coefficients were highly consistent across replicate runs. The bar plots indicated that some isolates are highly admixed, while others belong mostly to one particular cluster (Fig. 1). Isolates belonging to clusters one and seven presented fewer admixtures than individuals from other clusters. The type culture of $P$. capsici from New Mexico had membership predominantly in cluster three and partial membership in clusters four and eight, which was similar to cluster membership for current New Mexican samples. The type culture from Italy (year 1927) had membership mostly in cluster six and partial membership in clusters two and four, which was similar to cluster membership for current Italian samples.

Population structure was detected when data were organized using host categories as prior population information (Fig. 1A to C). Isolates from vegetable hosts contained representatives from all clusters but isolates belonging to cluster one occurred more frequently in nonvegetable than in vegetable hosts (Fig. 1A). F $_{\text {ST }}$ estimates indicated moderate differentiation between isolates from vegetable and nonvegetable hosts (Table 1). Diversity estimates for isolates from nonvegetable hosts were higher than from vegetable hosts (Table 2). Cucurbitaceous hosts presented individuals from all clusters, except for cluster two that was only sampled from solanaceous hosts (Fig. 1B) and was mostly associated to C. annuum, C. pubescens, and Solanum lycopersicon (Fig. 1C). Solanaceous hosts presented members from all clusters. The family Fabaceae had isolates from clusters four, five, seven, and eight. $\mathrm{F}_{\mathrm{ST}}$ values indicated low differentiation among isolates from hosts in the Fabaceae, Cucurbitaceae, and Solanaceae families (Table 1). The highest and lowest diversity estimates of isolates grouped by host family were observed for isolates from the Solanaceae and Cucurbitaceae families, respectively (Table 2 ). The pattern of cluster occurrence among cucurbit species was more similar than among solanaceous species. $C$. апnиит contained members from all clusters except for clusters one and seven, while $S$. melongena included several isolates belonging mostly to cluster seven. $\mathrm{F}_{\mathrm{ST}}$ estimates detected low differentiation among isolates from cucurbitaceous species but moderate to high differentiation between isolates from cucurbitaceous and solanaceous species and among isolates from solanaceous species (Table 1). The highest and lowest diversity estimates of isolates grouped by host species were observed for isolates from $C$. annuum and $C$. sativus, respectively (Table 2).

When geography categories were used as prior population information in the cluster analysis, some population structure was revealed (Fig. 2). Isolates from the Northern hemisphere were represented in all clusters while isolates from the Southern hemisphere contained less cluster diversity (Fig. 2A); this may be due to a greater sampling in the Northern versus Southern hemisphere. $\mathrm{F}_{\mathrm{ST}}$ estimates indicated moderate differentiation between isolates from the Northern and Southern hemispheres (Table 3). Diversity estimates for isolates from the Northern hemisphere were higher than those obtained for isolates from the Southern hemisphere (Table 4). Clusters four and eight were sampled from all continents. North America contained isolates from all clusters and isolates belonging to cluster five were only found in this continent (Fig. 2B). Isolates belonging to cluster two were present only in North and South America. Individuals from cluster six were primarily sampled in Europe. Members from cluster three were only found in North America and Asia, and both continents had the highest diversity of cluster occurrence. High genetic differentiation was detected between isolates from Europe and from all other continents according to $\mathrm{F}_{\mathrm{ST}}$ values (Table 3). Moderate to high genetic differentiation occurred among isolates 
from North America, South America, and Asia. The highest and lowest diversity estimates of isolates grouped by continent were observed in Europe and South America, respectively (Table 4).

$\mathrm{F}_{\mathrm{ST}}$ values showed high genetic differentiation between isolates from Italy and from all other countries and between isolates from Mexico and Taiwan (Table 3). When isolates were grouped by country, isolates from Italy and Taiwan showed the highest and lowest diversity estimates, respectively (Table 4). The U.S. contained isolates from all clusters, except for cluster one, which was associated with Guatemala and Mexico (Fig. 2D). Isolates from clusters five, seven, and nine were mostly sampled in the U.S., while isolates from clusters one and six were primarily found outside the U.S. (non-U.S.) (Fig. 2C). $\mathrm{F}_{\mathrm{ST}}$ estimates indicated moderate differentiation between isolates from the U.S. and nonU.S. regions (Table 3). Diversity estimates for non-U.S. isolates were higher than those obtained for U.S. isolates (Table 4). Michigan, North Carolina, New York, and Ohio; Arizona, New Mexico, and Texas; and California and Georgia presented similar patterns of cluster occurrence (Fig. 2E). California, South Carolina, and New Jersey presented more diversity of cluster occurrence than other states. Michigan and Massachusetts contained a high number of isolates from cluster three compared with other states. Tennessee only had isolates from cluster seven. $\mathrm{F}_{\mathrm{ST}}$ esti- mates indicated moderate to high differentiation between isolates from Michigan and from all other states and isolates from Tennessee and from all other states (Table 3). The highest and lowest diversity estimates of isolates grouped by U.S. state were observed in New Jersey and Tennessee, respectively (Table 4). South Carolina was the only state with members from cluster two, which was also found in South America. Isolates from cluster six that were mostly sampled in Europe were also found within the United States in California, Hawaii, and Florida. Individuals from clusters three, four, five, seven, eight, and nine were sampled across multiple states in the United States.

Some structure was identified in isolates intermediately sensitive and insensitive to mefenoxam (Supplementary Figure 1). The category sensitive to mefenoxam contained individuals from all clusters. The categories insensitive to mefenoxam and intermediately sensitive to mefenoxam did not contain isolates from cluster nine. $F_{\mathrm{ST}}$ values showed low to moderate genetic differentiation between sensitive and intermediately sensitive isolates and sensitive and insensitive isolates (Table 5). Genetic differentiation was very low between insensitive and intermediately sensitive isolates (Table 5). The highest diversity estimates were found for isolates sensitive to mefenoxam (Table 6). Diversity estimates for intermediately sensitive and insensitive isolates were
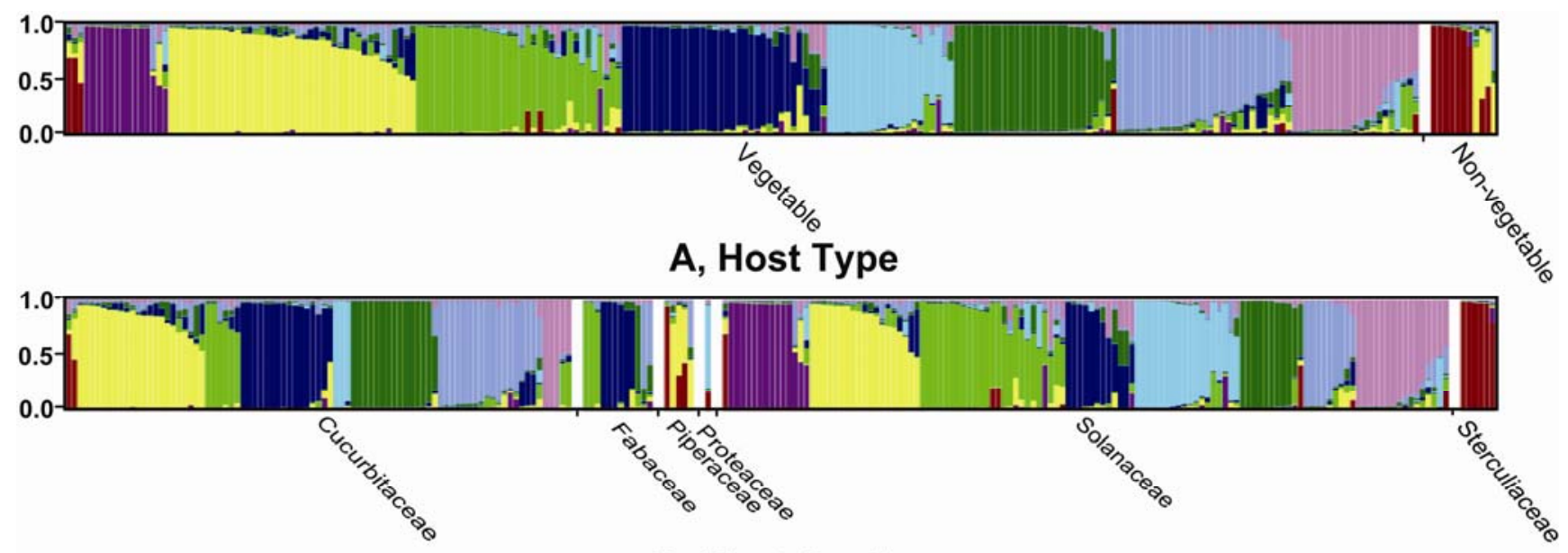

B, Host Family
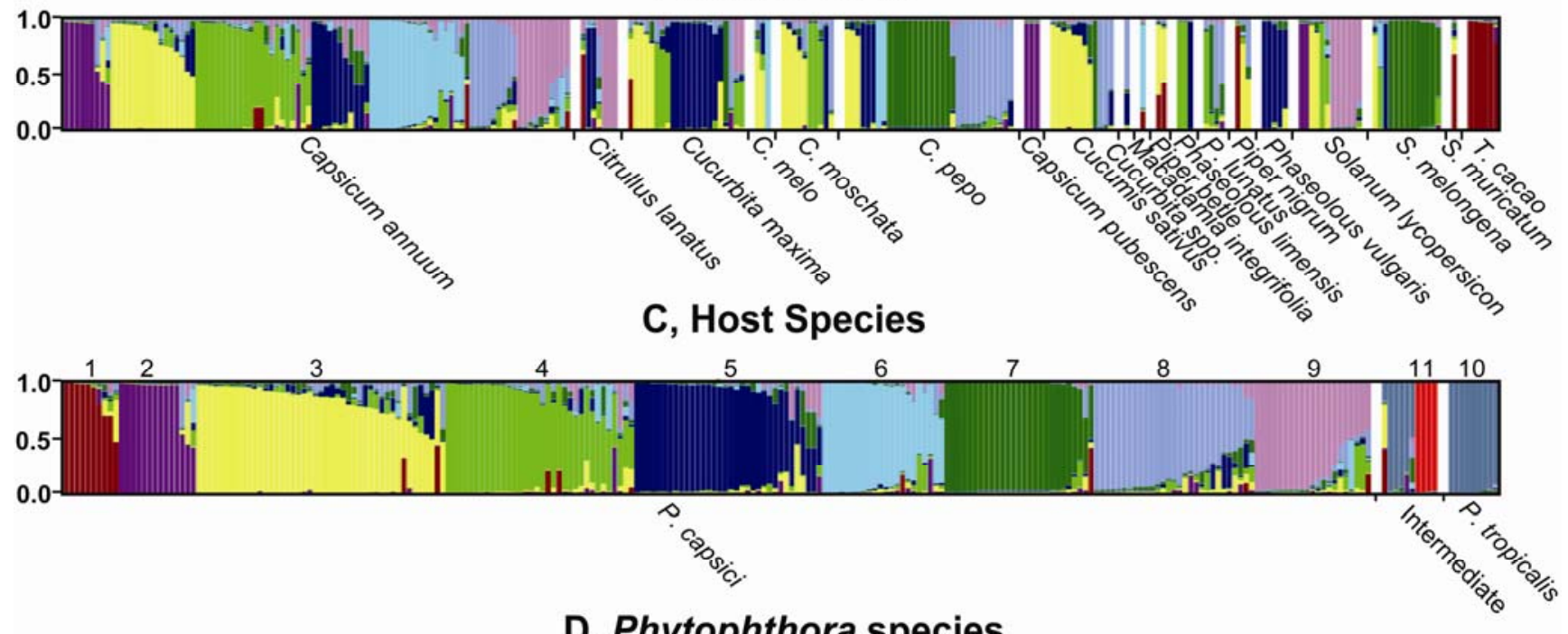

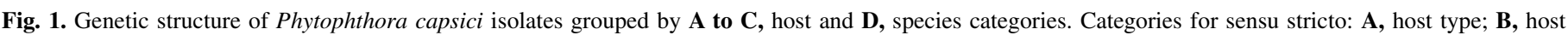

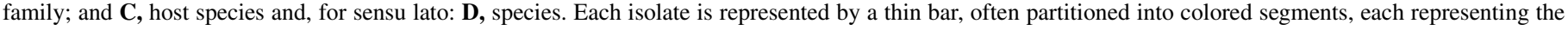

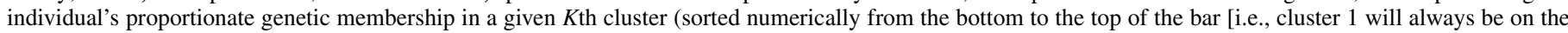

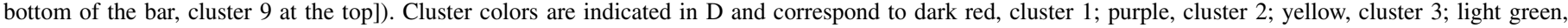

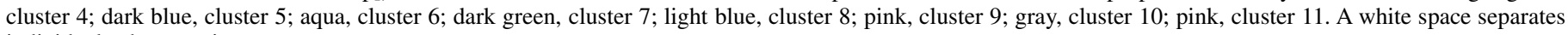
individual subcategories. 
comparable with each other (Table 6). Isolates insensitive and intermediately sensitive to mefenoxam were mostly found in North America, except for one isolate from Taiwan that was insensitive to mefenoxam and one from Taiwan and two from Spain that were intermediately sensitive to the fungicide. Isolates sensitive to mefenoxam were collected from many different regions of the world and hosts (Supplementary Table 1). P. capsici isolates insensitive and intermediately sensitive to mefenoxam originated from hosts belonging to the Cucurbitaceae, Fabaceae, Piperaceae, Solanaceae, and Sterculiaceae families.

No evident population structure was detected when the data were analyzed using MT (Supplementary Figure 1) as prior population information. Both MTs contained individuals from all clusters. $F_{\mathrm{ST}}$ values indicated very low genetic differentiation between $\mathrm{A} 1$ and $\mathrm{A} 2$ isolates (Table 5). Diversity estimates for A1 isolates were higher than those obtained for A2 isolates (Table 6). MT distribution in the total sample (A1: 125, A2: 121 for the total sample, binomial test $P=0.8484$ ) (Supplementary Table 1) for North America $(P=0.6426)$ and in countries including Brazil $(P=1.0000)$, Mexico $(P=1.0000)$, Taiwan $(P=1.0000)$, and the United States $(P=0.7497)$ was approximately $1: 1$. Countries such as Cameroon $(P=0.2500)$, Chile $(P=0.2500)$, China $(P=$ $0.500)$, Guatemala $(P=1.0000)$, Indonesia $(P=0.5000)$, Japan $(P=0.0625)$, Korea $(P=1.0000)$, Norway $(P=0.2500)$, Peru
$(P=0.2500)$, Spain $(P=0.1250)$, Thailand $(P=1.0000)$, Uruguay $(P=0.2500)$, and the former Yugoslavia $(P=1.0000)$ and continents (Africa $[P=0.2500]$ ) with a lower number of sampled isolates $(n<8)$ showed a prevalence of one MT over the other but this relationship was not statistically significant. For France $(P=$ $0.0312)$, the A1 MT was significantly more prevalent than the A2 MT, even with a sample size of six isolates. Other countries and continents with good sampling $(n>8)$ presented an increased number of A2 (South America $[P=0.7539]$ and Asia $[P=$ $0.2478]$ ) or $A 1$ isolates (Europe $[P=0.0125]$ and Italy $[P=$ $0.1796])$ but the ratio did not significantly differ from the expected 1:1 ratio except in Europe. Isolates obtained from cucurbitaceous, fabaceous, piperaceous, proteaceous, and solanaceous hosts also presented a 1:1 distribution of MTs $(P>0.2103)$. Isolates originating from the family Sterculiaceae presented deviations from the 1:1 MT distribution $(P=0.0312)$, with the A1 MT predominating.

When the structure of the SL data was analyzed, 11 clusters $(K=10, \ln \mathrm{P}=-6787 ; K=11, \ln \mathrm{P}=-6580 ; K=12, \ln \mathrm{P}=-6659)$ were detected, 2 more that were detected in SS (Fig. 1D). If each isolate was assigned to the $K$ th genetic cluster to which the isolate predominantly belonged, then 10 isolates belonged to cluster 1 , 13 isolates to cluster 2, 42 isolates to cluster 3, 32 isolates to cluster 4,30 isolates to cluster 5,22 isolates to cluster 6,26

TABLE 1. Average genetic differentiation estimates of mitochondrial and nuclear genes for Phytophthora capsici sensu stricto with isolates grouped in predefined host categories ${ }^{\mathrm{a}}$

\begin{tabular}{|c|c|c|c|c|c|c|c|c|c|c|c|c|c|c|c|c|c|c|}
\hline \multirow[b]{2}{*}{ Category } & \multicolumn{18}{|c|}{$\mathrm{F}_{\mathrm{ST}}$} \\
\hline & \multicolumn{2}{|c|}{ Vegetable } & \multicolumn{2}{|c|}{ Cucurbitaceae } & \multicolumn{2}{|c|}{ Fabaceae } & \multicolumn{2}{|c|}{$\begin{array}{l}\text { Capsicum } \\
\text { annuum }\end{array}$} & \multicolumn{2}{|c|}{$\begin{array}{l}\text { Cucurbita } \\
\text { maxima }\end{array}$} & \multicolumn{2}{|c|}{$\begin{array}{l}\text { Cucurbita } \\
\text { moschata }\end{array}$} & \multicolumn{2}{|c|}{$\begin{array}{c}\text { Cucurbita } \\
\text { pepo }\end{array}$} & \multicolumn{2}{|c|}{$\begin{array}{l}\text { Cucumis } \\
\text { sativus }\end{array}$} & \multicolumn{2}{|c|}{$\begin{array}{c}\text { Solanum } \\
\text { lycopersicon }\end{array}$} \\
\hline \multicolumn{19}{|l|}{ Host type } \\
\hline Nonvegetable & $0.12 *$ & $0.18^{*}$ & $\ldots$ & $\ldots$ & $\ldots$ & $\ldots$ & $\ldots$ & $\ldots$ & $\ldots$ & $\ldots$ & $\ldots$ & $\ldots$ & $\ldots$ & $\ldots$ & $\ldots$ & $\ldots$ & $\ldots$ & $\ldots$ \\
\hline \multicolumn{19}{|l|}{ Host family } \\
\hline Fabaceae & $\ldots$ & $\ldots$ & 0.01 & $0.03^{*}$ & $\ldots$ & $\ldots$ & $\ldots$ & $\ldots$ & $\ldots$ & $\ldots$ & $\ldots$ & $\ldots$ & $\ldots$ & $\ldots$ & $\ldots$ & $\ldots$ & $\ldots$ & $\ldots$ \\
\hline Solanaceae & $\ldots$ & $\ldots$ & 0.02 & $0.04 *$ & $0.04 *$ & $0.03^{*}$ & $\ldots$ & $\ldots$ & $\ldots$ & $\ldots$ & $\ldots$ & $\ldots$ & $\ldots$ & $\ldots$ & $\ldots$ & $\ldots$ & $\ldots$ & $\ldots$ \\
\hline \multicolumn{19}{|l|}{ Host species } \\
\hline Cucurbita maxima & $\ldots$ & $\ldots$ & $\ldots$ & $\ldots$ & $\ldots$ & $\ldots$ & $0.05^{*}$ & $0.03 *$ & $\ldots$ & $\ldots$ & $\ldots$ & $\ldots$ & $\ldots$ & $\ldots$ & $\ldots$ & $\ldots$ & $\ldots$ & $\ldots$ \\
\hline C. moschata & $\ldots$ & $\ldots$ & $\ldots$ & $\ldots$ & $\ldots$ & $\ldots$ & $0.10^{*}$ & $0.04 *$ & $0.02 *$ & $0.02 *$ & $\ldots$ & $\ldots$ & $\ldots$ & $\ldots$ & $\ldots$ & $\ldots$ & $\ldots$ & $\ldots$ \\
\hline C. реро & $\ldots$ & $\ldots$ & $\ldots$ & $\ldots$ & $\ldots$ & $\ldots$ & $0.06^{*}$ & $0.05^{*}$ & 0.00 & $0.03 *$ & $0.03 *$ & $0.02 *$ & $\ldots$ & $\ldots$ & $\ldots$ & $\ldots$ & $\ldots$ & $\ldots$ \\
\hline Cucumis sativus & $\ldots$ & $\ldots$ & $\ldots$ & $\ldots$ & $\ldots$ & $\ldots$ & $0.10^{*}$ & $0.08^{*}$ & 0.00 & $0.05^{*}$ & $0.03^{*}$ & $0.03^{*}$ & 0.02 & $0.03 *$ & $\ldots$ & $\ldots$ & $\ldots$ & $\ldots$ \\
\hline S. lycopersicon & $\ldots$ & $\ldots$ & $\ldots$ & $\ldots$ & $\ldots$ & $\ldots$ & $0.10^{*}$ & $0.05^{*}$ & 0.00 & $0.10^{*}$ & $0.03 *$ & $0.14^{*}$ & 0.02 & $0.13^{*}$ & 0.00 & $0.17 *$ & $\ldots$ & $\ldots$ \\
\hline S. melongena & $\ldots$ & $\ldots$ & $\ldots$ & $\ldots$ & $\ldots$ & $\ldots$ & $0.08 *$ & $0.15^{*}$ & 0.00 & $0.18^{*}$ & $0.03^{*}$ & $0.20 *$ & 0.02 & $0.19^{*}$ & 0.00 & $0.28 *$ & 0.00 & $0.22 *$ \\
\hline
\end{tabular}

${ }^{a}$ Categories with fewer than eight isolates were excluded from analyses and are not shown. Reported values correspond to average values for mitochondrial (left column) and nuclear genes (right column); $*$ significant at 0.05 .

TABLE 2. Average diversity estimates of mitochondrial and nuclear genes for Phytophthora capsici sensu stricto (SS) with isolates grouped in predefined host categories

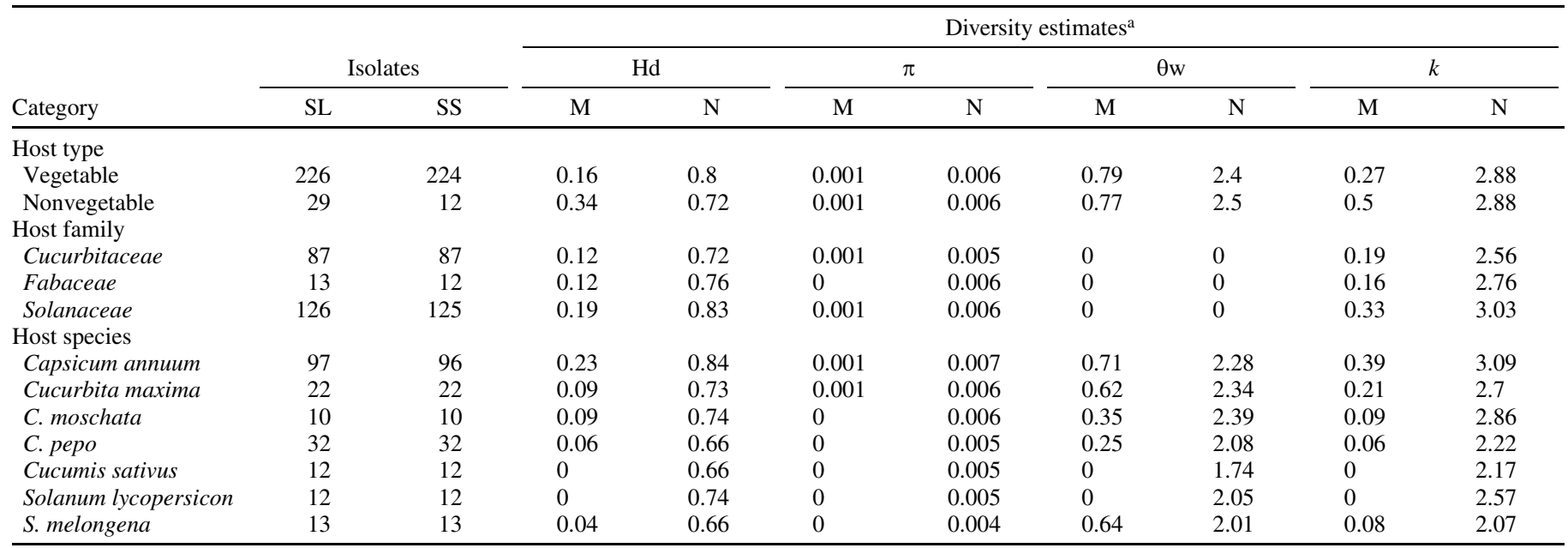

${ }^{a}$ Categories with fewer than eight isolates were excluded from analyses and are not shown. $\mathrm{Hd}=$ haplotype diversity, $\pi=$ Tajima's $\pi, k=$ the average number of pairwise nucleotide differences, and $\theta \mathrm{w}=$ Watterson's theta. Reported values correspond to average values for mitochondrial (M, left column) and nuclear genes $(\mathrm{N}$, right column). 
isolates to cluster 7, 29 isolates to cluster 8,18 isolates to cluster 9,14 isolates to cluster 10 , and 4 isolates to cluster 11 . Fifteen isolates were not $>0.1$ (proportion membership) higher in one genetic cluster than another and could not be assigned predominant cluster membership. Individual ancestry coefficients were highly consistent across replicate runs, as was observed for $\mathrm{SS}$. Isolates belonging to cluster 10 presented some admixture with SS clusters and isolates from cluster 11 showed no admixture. More admixture was observed in clusters generated from the SS group. When the data were analyzed using the categories $P$. capsici, intermediate, and $P$. tropicalis as prior population information, no genetic clustering directly corresponding to the categories was observed. However, some structure was observed in each category. The $P$. capsici category contained the same clusters detected in SS and no individuals from clusters 10 and 11. The intermediate group presented isolates from clusters 10 and 11 and some admixed individuals with partial membership in SS clusters and cluster 10 . The $P$. tropicalis group only contained isolates from cluster 10 that showed very little admixture and included the type culture of $P$. tropicalis. Isolates from cluster 10 originated from Mexico, India, Australia, and Hawaii from tropical hosts and from Delaware from lima bean. Isolates from cluster 11 presented no admixture and corresponded to intermediate isolates from Brazil and Michigan obtained from cacao and English Ivy (Hedera helix), respectively. Morphological characteristics of all isolates were consistent with the description of $P$. capsici included in the Phytophthora spp. key by Waterhouse (83).

The highest values of genetic differentiation observed in this study occurred between $P$. capsici and non- $P$. capsici isolates (Table 5). Diversity estimates for $P$. capsici isolates were lower than those obtained for non- $P$. capsici isolates (Table 6; Supplementary Table 4). The NeighborNet networks for genes HSP90, TigA, EF-1 $\alpha, \beta$-Tubulin, Ura3, and Cox 1 showed three groups of haplotypes with moderate $(>65)$ to high $(>90)$ bootstrap support. The three groups presented several incompatibilities within each group but few or no incompatibilities among groups, depending on the gene (Supplementary Figure 2). These groups were not contradicted by the other genealogies but grouping of isolates had less resolution. Isolates belonging to the first group of haplotypes corresponded to $P$. capsici $\mathrm{SS}$, while isolates belonging to the second and third groups of haplotypes included isolates from clusters 10 and 11 , respectively. For $P$. capsici SS isolates, no distinctive groups of haplotypes with high bootstrap support were

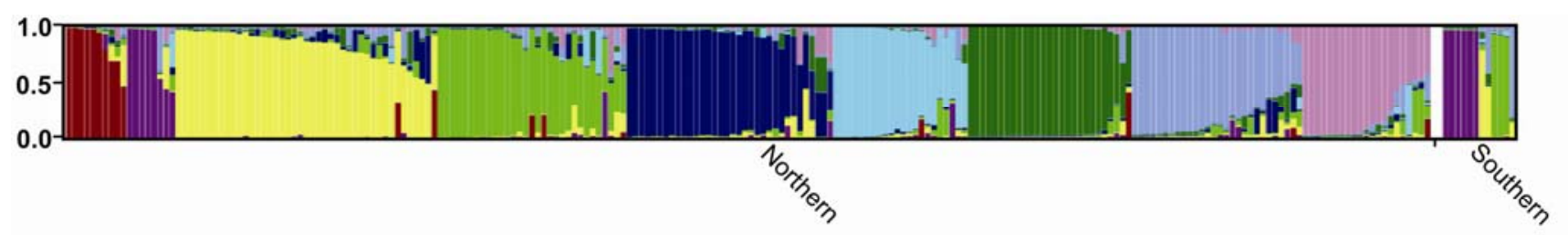

A, Hemisphere

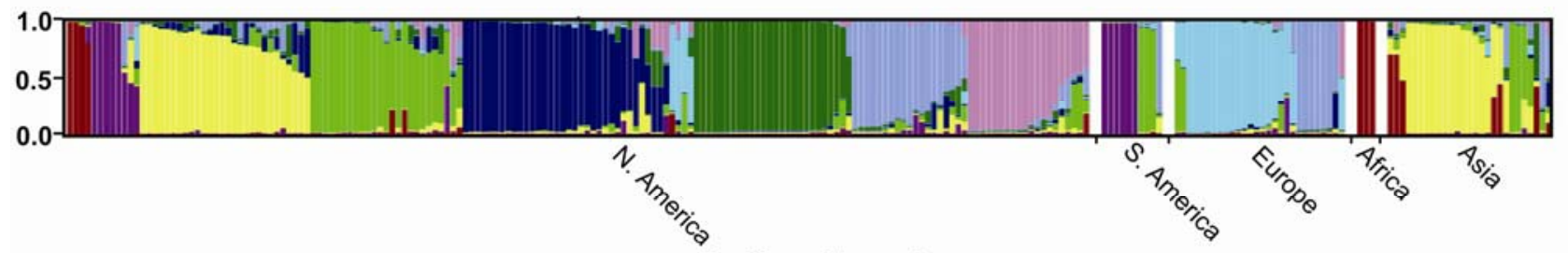

B, Continent
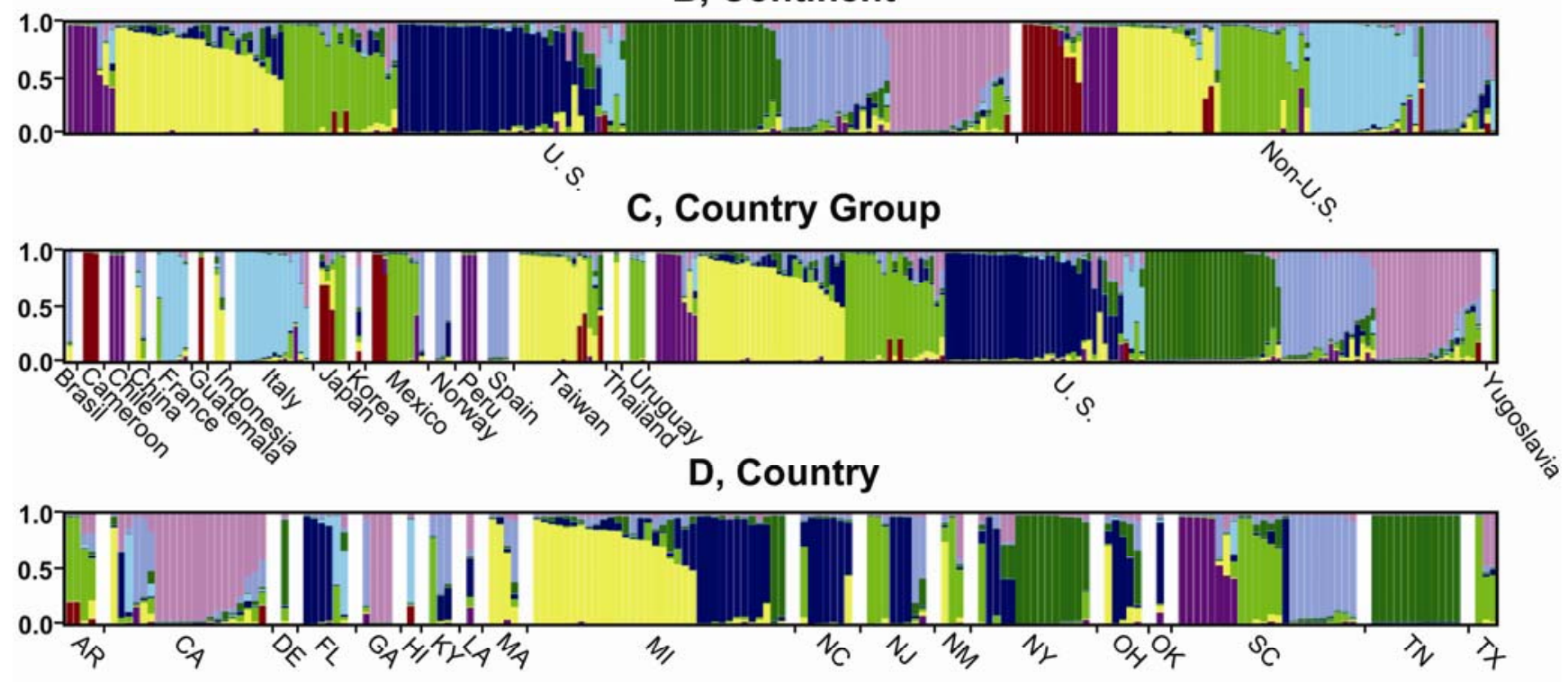

E, U.S. State

Fig. 2. Genetic structure of Phytophthora capsici isolates grouped by predefined geographic categories. Categories for sensu stricto: A, hemisphere; B, continent; C, country group; D, country; and E, U.S. state. Geographic origin abbreviations: U.S., United States, and standard abbreviations for U.S. states. Each isolate is represented by a thin bar, often partitioned into colored segments, each representing the individual's proportionate genetic membership in a given $K$ th cluster (sorted numerically from the bottom to the top of the bar [i.e., cluster 1 will always be on the bottom of the bar, cluster 9 at the top]). Cluster colors correspond to: dark red-one, cluster 1; purple, cluster 2; yellow, cluster 3; light green, cluster 4; dark blue, cluster 5; aqua, cluster 6; dark green, cluster 7; light blue, cluster 8; pink, cluster 9. A white space separates individual subcategories. 
consistently observed in all or most networks. Networks overall indicated significant incompatibility within nuclear genes, and the highest number of incompatibilities was observed in Ura3. The mitochondrial genes presented a few incompatibilities, and Cox2 showed no networking. Statistical parsimony haplotype genealo- gies for SL presented a topology similar to the NeighborNet networks (Fig. 3; Supplementary Figure 3). P. capsici SS haplotypes appeared to be very closely related to each other, with only one or two missing haplotypes separating sampled haplotypes. Haplotypes from clusters 10 and 11 were more distantly related to

TABLE 3. Average genetic differentiation estimates of mitochondrial and nuclear genes for Phytophthora capsici sensu stricto with isolates grouped in predefined geographic categories

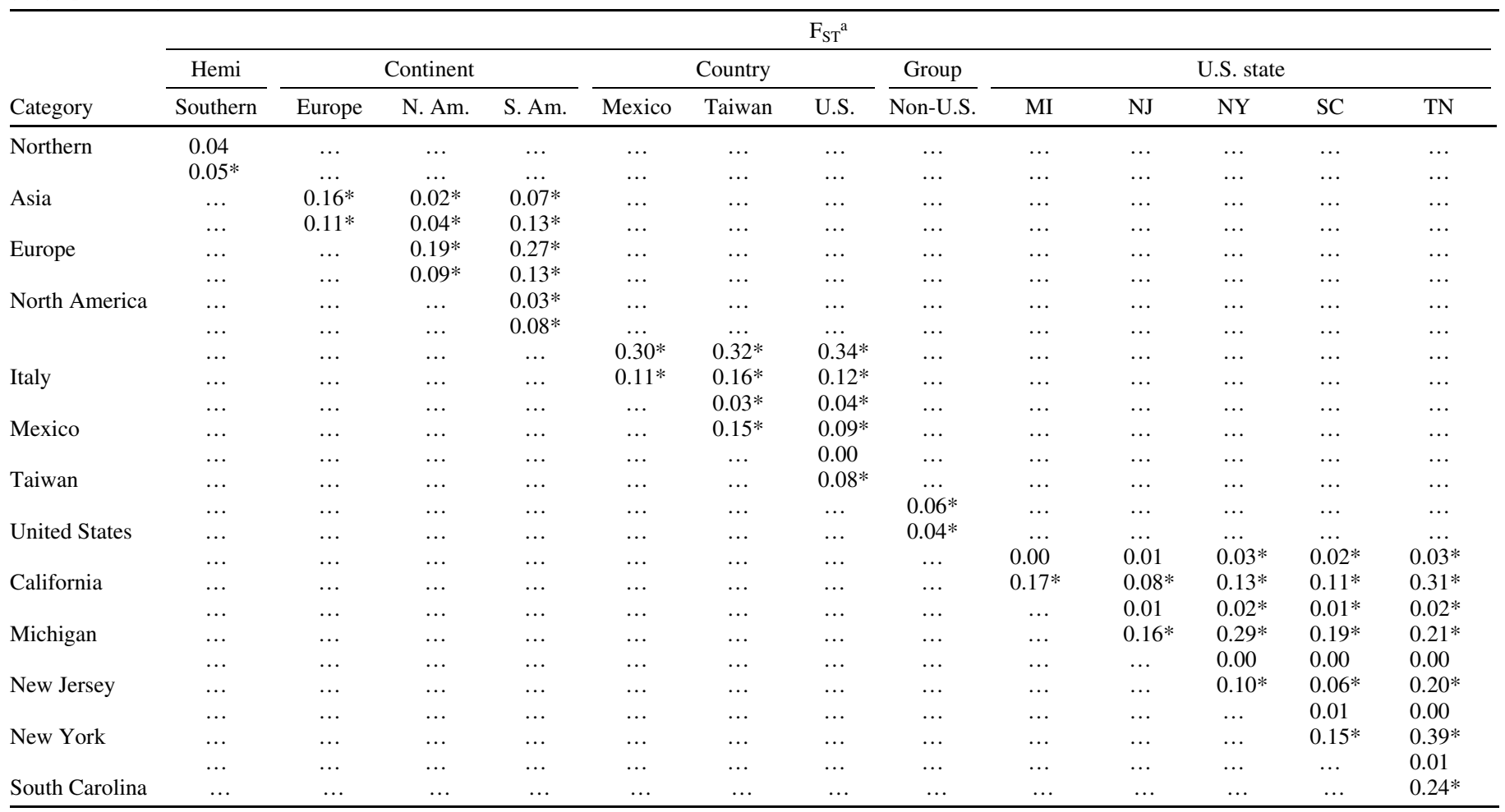

a Abbreviations: Hemi $=$ hemisphere, Group $=$ country group, N. Am. $=$ North America, S. Am. $=$ South America, MI $=$ Michigan, NJ $=$ New Jersey, NY = New York, SC = South Carolina, and TN = Tennessee. Categories with fewer than eight isolates were excluded from analyses and are not shown. Reported values correspond to average values for mitochondrial (upper) and nuclear genes (lower); * $=$ significant at 0.05 .

TABLE 4. Diversity estimates of mitochondrial and nuclear genes for Phytophthora capsici sensu stricto (SS) with isolates grouped in predefined geographic categories

\begin{tabular}{|c|c|c|c|c|c|c|c|c|c|c|}
\hline \multirow[b]{3}{*}{ Category } & & & \multicolumn{8}{|c|}{ Diversity estimates $^{\mathrm{a}}$} \\
\hline & \multicolumn{2}{|c|}{ Isolates } & \multicolumn{2}{|c|}{$\mathrm{Hd}$} & \multicolumn{2}{|c|}{$\pi$} & \multicolumn{2}{|c|}{$\theta \mathrm{w}$} & \multicolumn{2}{|c|}{$k$} \\
\hline & SL & SS & M & $\mathrm{N}$ & M & $\mathrm{N}$ & M & $\mathrm{N}$ & M & $\mathrm{N}$ \\
\hline Northern & 235 & 224 & 0.19 & 0.81 & 0.001 & 0.006 & 0.79 & 2.50 & 0.32 & 2.94 \\
\hline Southern & 20 & 12 & 0.08 & 0.76 & 0.000 & 0.006 & 0.33 & 2.10 & 0.08 & 2.65 \\
\hline \multicolumn{11}{|l|}{ Continent } \\
\hline Asia & 28 & 27 & 0.21 & 0.77 & 0.001 & 0.006 & 0.65 & 2.45 & 0.40 & 2.66 \\
\hline South America & 13 & 10 & 0.00 & 0.74 & 0.000 & 0.005 & 0.00 & 1.97 & 0.00 & 2.57 \\
\hline \multicolumn{11}{|l|}{ Country } \\
\hline Italy & 14 & 14 & 0.28 & 0.83 & 0.001 & 0.006 & 0.78 & 2.36 & 0.52 & 2.73 \\
\hline Mexico & 13 & 10 & 0.21 & 0.76 & 0.001 & 0.007 & 0.53 & 2.30 & 0.32 & 3.14 \\
\hline Taiwan & 16 & 16 & 0.12 & 0.73 & 0.001 & 0.005 & 0.68 & 1.78 & 0.28 & 2.16 \\
\hline United States & 164 & 157 & 0.11 & 0.77 & 0.001 & 0.006 & 0.71 & 2.34 & 0.19 & 2.77 \\
\hline \multicolumn{11}{|l|}{ Country group } \\
\hline Michigan & 35 & 34 & 0.08 & 0.59 & 0.000 & 0.004 & 0.73 & 1.60 & 0.17 & 1.96 \\
\hline New Jersey & 8 & 8 & 0.12 & 0.79 & 0.001 & 0.006 & 0.58 & 2.36 & 0.19 & 2.93 \\
\hline New York & 15 & 15 & 0.00 & 0.67 & 0.000 & 0.005 & 0.00 & 1.85 & 0.00 & 2.14 \\
\hline South Carolina & 24 & 24 & 0.06 & 0.78 & 0.000 & 0.007 & 0.40 & 2.21 & 0.08 & 3.17 \\
\hline Tennessee & 12 & 12 & 0.00 & 0.26 & 0.000 & 0.002 & 0.00 & 0.71 & 0.00 & 0.70 \\
\hline
\end{tabular}

${ }^{a}$ Categories with fewer than eight isolates were excluded from analyses and are not shown. $\mathrm{Hd}=$ haplotype diversity, $\pi=$ Tajima's $\pi, k=$ the average number of pairwise nucleotide differences, and $\theta \mathrm{w}=$ Watterson's theta. Reported values correspond to average values for mitochondrial (M, left column) and nuclear genes $(\mathrm{N}$, right column). 
$P$. capsici SS, with two or more missing haplotypes separating both clades, which was supported by all genealogies. All genealogies except TigA presented some $P$. capsici SS haplotypes that included one or two alleles of isolates from clusters 10 and 11. In some genealogies, several haplotypes corresponding to clusters 10 or 11 were grouped together and separated from each other and from $P$. capsici by at least one missing haplotype (Cox1, Cox2, Nad1, EF-1 $\alpha$, and TigA). Some SS haplotypes were frequently sampled and found throughout the world on diverse hosts, while other haplotypes sampled at lower frequencies originated from specific states, countries, continents, and hosts (Supplementary Table 1).

\section{DISCUSSION}

P. capsici is an economically important plant pathogen with a wide geographic and host range, as reflected by the sampling in this study. To detect population structure and determine whether predefined categories based on host, geography, mefenoxam sensitivity, or MT reflect genetic relationships among $P$. capsici isolates, we sequenced 10 genes from 255 individuals to perform population structure analyses. Bayesian clustering of isolates identified 9 and 11 major genetically distinct clusters in SS and SL, respectively. Clustering analysis revealed some population structure by host, geographic origin, and mefenoxam sensitivity in SS and by species in SL, with some clusters occurring more or less frequently in particular categories. However, it showed no direct correspondence between any of the predefined categories and the number of inferred clusters. Pairwise $\mathrm{F}_{\mathrm{ST}}$ comparisons and genetic diversity estimates among predefined host, geography, mefenoxam-sensitivity, MT, and species categories were consistent with the distribution of genetic variation detected by
Bayesian clustering and provided additional information on the genetic variability within and between categories.

When isolates were grouped by host, differences in frequency of occurrence of certain clusters in particular hosts were observed. Isolates from cluster one occurred more frequently in nonvegetable hosts (cacao and black pepper) than in vegetable hosts. A previous study in $P$. capsici found temperate isolates from vegetable hosts (Solanaceae, Cucurbitaceae, and Fabaceae families) to be grouped together in the same clade, whereas tropical isolates appeared to have different genetic lineages (7), in agreement with our findings. Nonetheless, that study did not determine whether isolates corresponded only to $P$. capsici or whether P. tropicalis was present in their sample; therefore, it is not possible to determine whether $P$. capsici SS isolates were truly associated with tropical (nonvegetable) hosts or whether isolates from tropical hosts corresponded only to P. tropicalis and isolates assigned to cluster 11. Work by Donahoo and Lamour detected phylogenetic clustering of $P$. capsici SS isolates from tropical hosts (nonvegetable) in a separated but closely related clade from isolates from vegetable hosts (10), which further supports our findings of genetic differentiation between these categories. Tropical hosts of $P$. capsici have more woody tissue if compared with hosts from the Cucurbitaceae, Solanaceae, and Fabaceae families. In previous studies, it has been observed that $P$. capsici is difficult to recover from woody tissue of Fraser fir (65), oak (9), and various ornamentals (30). It is possible that isolates from different $P$. capsici clusters are not equally adapted to woody or herbaceous tissue, and this could result in isolates from a specific cluster such as cluster one occurring more frequently in woody hosts. A similar adaptation could be the cause of the almost exclusive association of cluster two with the Solanaceae family. Despite the large sampling in the Cucur-

TABLE 5. Average genetic differentiation estimates of mitochondrial and nuclear genes for Phytophthora capsici sensu stricto with isolates grouped in predefined mating-type and mefenoxam-sensitivity categories, and $P$. capsici sensu lato with isolates grouped by species category

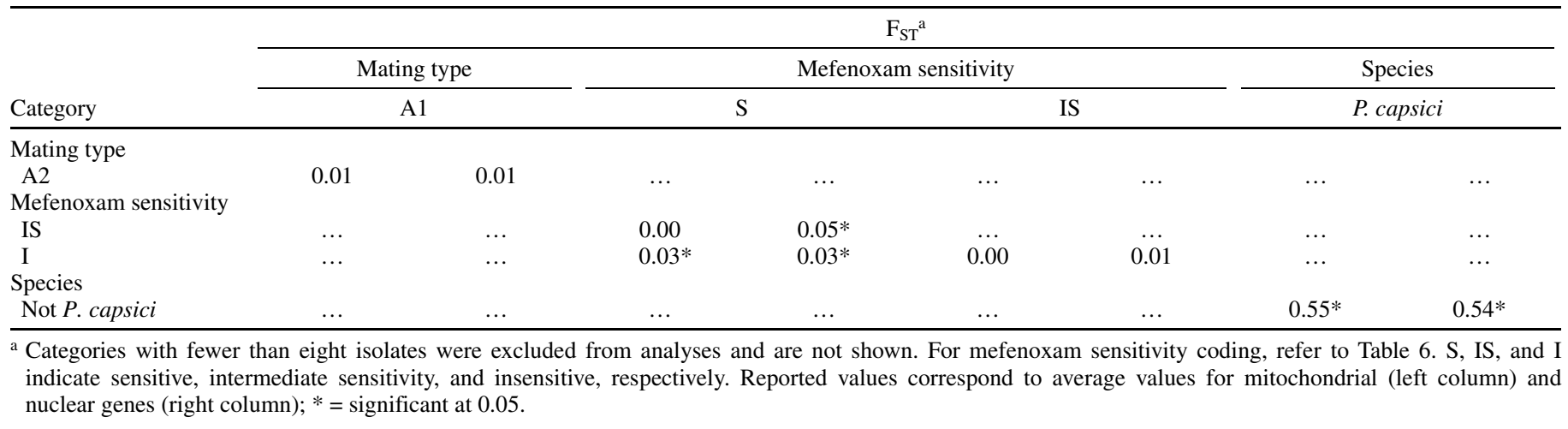

TABLE 6. Diversity estimates of mitochondrial and nuclear genes for Phytophthora capsici and sensu stricto (SS) with isolates grouped in predefined mating type and mefenoxam-sensitivity categories, and P. capsici sensu lato (SL) with isolates grouped by species category

\begin{tabular}{|c|c|c|c|c|c|c|c|c|c|c|}
\hline \multirow[b]{3}{*}{ Category } & & & \multicolumn{8}{|c|}{ Diversity estimates $^{\mathrm{a}}$} \\
\hline & \multicolumn{2}{|c|}{ Isolates } & \multicolumn{2}{|c|}{$\mathrm{Hd}$} & \multicolumn{2}{|c|}{$\pi$} & \multicolumn{2}{|c|}{$\theta \mathrm{w}$} & \multicolumn{2}{|c|}{$k$} \\
\hline & SL & SS & M & $\mathrm{N}$ & M & $\mathrm{N}$ & M & $\mathrm{N}$ & M & $\mathrm{N}$ \\
\hline A1 & 73 & 64 & 0.22 & 0.81 & 0.001 & 0.006 & 0.83 & 2.54 & 0.37 & 2.99 \\
\hline A2 & 76 & 66 & 0.15 & 0.78 & 0.001 & 0.007 & 0.69 & 2.31 & 0.23 & 3.18 \\
\hline \multicolumn{11}{|c|}{ Mefenoxam sensitivity } \\
\hline $\mathrm{S}$ & 218 & 201 & 0.20 & 0.81 & 0.001 & 0.006 & 0.76 & 2.51 & 0.33 & 2.93 \\
\hline \multicolumn{11}{|l|}{ Species } \\
\hline Not P. capsici & 19 & 0 & 0.77 & 0.72 & 0.009 & 0.015 & 2.79 & 7.02 & 3.30 & 7.06 \\
\hline
\end{tabular}

${ }^{a}$ Categories with fewer than eight isolates were excluded from analyses and are not shown. $\mathrm{Hd}=$ haplotype diversity, $\pi=$ Tajima's $\pi, k=$ the average number of pairwise nucleotide differences, and $\theta \mathrm{w}=$ Watterson's theta. For mefenoxam sensitivity coding, refer to Table 6 . S, IS, and I indicate sensitive, intermediate sensitivity, and insensitive, respectively. Reported values correspond to average values for mitochondrial ( $\mathrm{M}$, left column) and nuclear genes (N, right column). 
bitaceae family $(n=87)$, no isolates belonging predominately to cluster two were found in hosts from this family. As with the woody hosts, it is possible that isolates from cluster two are not able to infect members of the Cucurbitaceae family as frequently as members of the Solanaceae family. Overall, isolates from solanaceous hosts appeared to be more diverse in our sampling but additional analyses with an equal sampling of isolates from each family would be necessary to confirm this observation.

Evidence of clustering should not be taken as evidence of physiological races or pathotypes because we did not associate virulence data with the genetic clusters in the current study. We associated occurrence of clusters in a host. Differences in virulence and pathogenicity have been reported between isolates occurring in the families Solanaceae and Cucurbitaceae $(16,47,61,66,68)$ but the genetic basis of these differences is unknown. Experiments that associate virulence and pathogenicity with particular clusters are needed to determine whether cluster membership may be used to predict the occurrence of certain isolates in particular hosts and the virulence of the isolates. If such an association is found, cluster information could be applied to determine the most likely sources of virulent strains, which could be used for robust disease screenings in the search for resistant cultivars. The differences in cluster occurrence by host of origin found in this study have significant implications for the development of resistant cultivars. Breeding programs should include isolates that represent the genetic diversity of the pathogen in resistance screenings. Isolates obtained from hosts belonging to the Cucurbitaceae and Solanaceae families are commonly used in host resistance screenings $(16,66)$ but this study suggests that inclusion of isolates from tropical hosts that show high genetic variation is necessary to capture the genetic diversity of $P$. capsici.

Several studies examining samples of $P$. capsici isolates from different geographic locations worldwide have been published; however, clear detection of distinct subgroups in $P$. capsici based on geographic origin through phylogenetic methods remains elusive $(7,10,15,88)$. Some geographic structure was detected in our study. Some clusters occurred in all continents (four and eight), others were only present in select continents (two in North and South America) or were more frequently sampled in certain continents (six in Europe and three in North America and Asia) and countries (five, seven, and nine in the United States). North America and Asia presented a more diverse occurrence of clusters compared with other regions. The high diversity of $P$. capsici clusters found in the United States may challenge local breeding efforts. Breeding programs usually have a regional focus, where resistance for local pathogen populations is incorporated into host cultivars. Breeders working in areas with lower genetic diversity of the pathogen may have a higher chance of identifying cultivars resistant to local $P$. capsici populations (36). P. capsici populations with high levels of genetic variation are likely to adapt more rapidly to resistant hosts than populations with little genetic variation $(36,41)$. In our study, regions including Cameroon, Chile, Peru, France, Italy, Norway, Spain, Uruguay, and Tennessee presented a predominant cluster. The absence of other clusters is probably due to our sampling, but clonal $P$. capsici populations have been identified in Argentina (24) and Peru (36) in more robust sampling efforts. Local population studies with intensive sampling are needed to characterize and determine the spatial genetic structure of $P$. capsici populations on a finer scale than examined in the present work. However, establishing the spatial distribution of the nine $P$. capsici clusters detected in this study provides an initial map of global population structure that will help in isolate selection for resistance screening and will guide future sampling to expand our knowledge of $P$. capsici population structure.

$P$. capsici is water dispersed within fields and can be introduced into new fields through infected plant material or infested soil, tools, and irrigation water $(22,32)$. Wind dispersal is not an important mechanism for long-distance movement of $P$. capsici (29) and human activity likely plays a role in genetic structuring of populations. Migration of a few individuals per generation is sufficient to keep $\mathrm{F}_{\mathrm{ST}}$ values at $\leq 0.1$ (31). The observed Wright's $F_{\text {ST }}$ values between several regions suggest that movement among locations is rare but historical information indicates it is possible. It has been suggested that $P$. capsici was introduced to the United States through contaminated pepper seed that entered New Mexico (1918) (48) and Florida (1932) (85) because some of the earliest reports of this pathogen in the United States come from those states (41). Because a type culture of P. capsici from New Mexico was included in this study and had membership mostly in cluster three and partial membership in clusters four and eight, we know those clusters were present in New Mexico in 1965. Present samples from New Mexico also had membership in those clusters, indicating that cluster variation is maintained within populations; however, information about the genetic diversity of those isolates is not available because our sample was smaller than eight isolates. Genetic diversity estimates for New Jersey, South Carolina, and California isolates were higher than for other states, which
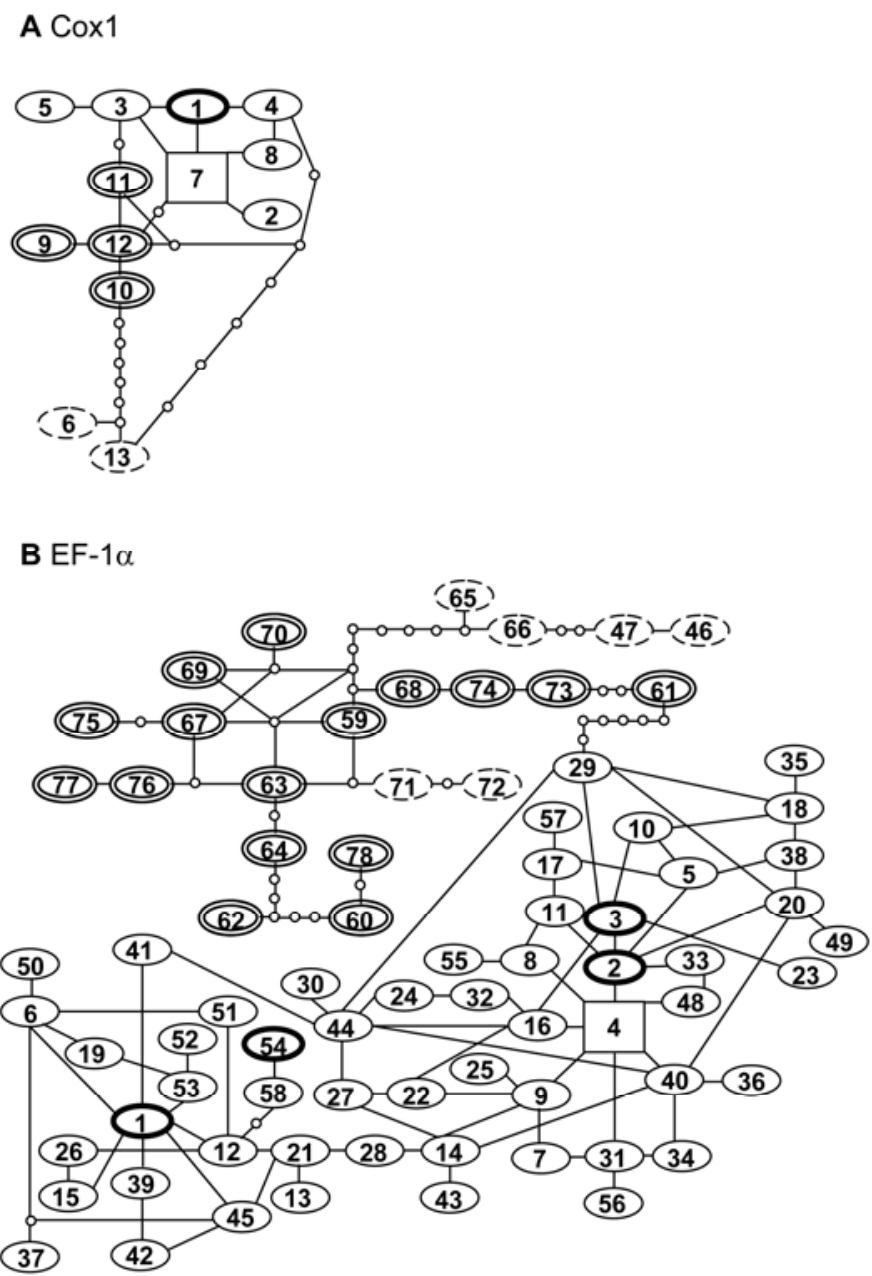

Fig. 3. Haplotype genealogies of Phytophthora capsici sensu lato mitochondrial and nuclear genes. A, Mitochondrial gene: Cox1. B, Nuclear gene: EF-1 $\alpha$. Other genes are shown in Supplementary Figure 3. Lines in the network represent possible paths of evolution. The haplotype with the highest probability to be ancestral is indicated by a square and other haplotypes are displayed as ovals. Empty dots represent missing or extant haplotypes. Bold ovals or squares indicate haplotypes that contain $P$. capsici sensu stricto isolates and isolates from clusters 10 or 11 . Dashed ovals or squares indicate haplotypes that contain isolates from cluster 10. Double-line ovals or squares indicate haplotypes that contain isolates from cluster 11. Dotted-line ovals or squares indicate haplotypes that contain both cluster 10 and 11 isolates. 
could be due to the longer presence of $P$. capsici in these states compared with Tennessee, New York, and Michigan. The type culture from Italy (year 1927) had membership mostly in cluster six and partial membership in clusters two and four, indicating that members of those clusters have been present in Italy since 1927, as reflected by the other Italian samples. Italian samples presented high levels of genetic variation that could be reflecting the long-term presence of $P$. capsici in Italy and subsequent diversification of isolates. Members of cluster six that were mostly sampled in Europe and, specifically, in Italy were also found in Hawaii, California, and Florida. It is possible that those U.S. isolates belonging to cluster six were introduced into the United States from Europe. Shared membership in a particular genetic cluster corresponds with shared ancestry in a particular population (k) (63). Our analysis provides a global framework to hypothesize about migration but evolutionary studies with appropriate markers are needed to determine migration pathways of $P$. capsici, as has been done with other pathogens $(25,28)$. Such studies will provide valuable information for regulatory measures and may also identify the center of origin of $P$. capsici, which could guide samplings of resistant germplasm.

Some structure was detected in isolates grouped by mefenoxam sensitivity, where sensitive isolates contained members from all clusters but intermediately sensitive and insensitive isolates did not contain members from cluster nine. Isolates belonging predominantly to cluster nine $(n=18)$ were sampled in California and Georgia from pepper, tomato, and watermelon. Because we do not know the fungicide history for the fields from which these samples were collected, it is possible that mefenoxam was not used; it may be that our limited sampling simply did not include isolates that belong to cluster nine and are insensitive to mefenoxam. Isolates from Spain, Taiwan, Mexico, and the United States were found to be intermediately sensitive or insensitive to mefenoxam. Other studies have found isolates insensitive to mefenoxam in Italy (60) and the United States (18,32). Isolates sensitive to mefenoxam were sampled from more regions and hosts than isolates intermediately sensitive or insensitive to mefenoxam. Continued characterization of $P$. capsici populations for mefenoxam insensitivity will help determine whether mefenoxam is still an effective control method in a particular field or whether other products are needed.

No structure was detected when isolates were grouped by MT, and all clusters were sampled in A1 and A2 isolates. A previous study also found no correlation between restriction fragment length polymorphism lineages and MT in isolates from New Mexico, Europe, and Korea (38). Regions with lower sampling showed the prevalence of only one MT, whereas regions with higher sampling contained both $\mathrm{A} 1$ and $\mathrm{A} 2$ isolates. Because recombination via sexual reproduction generates high genetic variability in $P$. capsici that may result in isolates with increased virulence or fungicide resistance, it is important to know the distribution of MTs in different regions. If only one MT is present in a field, country, or state, efforts should be directed to avoid the introduction of the other MT so that the long-term efficacy of control methods such as host resistance and fungicides is not reduced.

High genetic diversity has been previously reported for $P$. capsici $(39,44,73)$. Individuals with partial membership in several clusters, unique haplotypes (20 to $40 \%$ ), and unique multi-locus genotypes $(86 \%)$ reported here and in previous studies (70 to $90 \%)(43,44)$ are consistent with sexual reproduction in $P$. capsici (26), in contrast to the clear clonal structure that has been observed for other Phytophthora spp. such as P. infestans (27) and $P$. ramorum (64). Although admixture could be due to factors such as ancestral polymorphism, at least some admixture is likely a result of recombination, as indicated by recombination estimates for nuclear genes (75), incompatibilities observed in the NeighborNet networks, and extensive networking in statistical parsimony genealogies. Although these findings are unsurprising in light of previous studies (42-44), the implications of these results for choosing the best method to analyze populations of $P$. capsici are significant. Traditional phylogenetic methods have been used to study intraspecific population data of $P$. capsici $(7,10,88)$ even though recombination occurs frequently. Yet such methods are only appropriate under the assumption that recombination does not occur $(62,86)$. If recombination occurs frequently in the plant pathogen of interest, methods such as Bayesian clustering, split networks, and statistical parsimony that allow for recombination events should be used $(4,62)$. Bayesian clustering allows for the reconstruction of ancestral population structure and subsequent admixture in highly recombining species without subjective definitions of population groups or categories (86) and constitutes a useful tool to study population structure in P. capsici.

Characterization of genetic structure of $P$. capsici SS populations revealed moderate but significant population structure by host, geography, and mefenoxam sensitivity. Beyond the direct application of this knowledge in breeding efforts and development of fungicides, the detection of population structure in $P$. capsici has implications in using association genetics to identify the genetic basis of phenotypes of importance. Association studies have been performed to identify the genetic basis of disease in humans (20) and agronomic traits in plants (33). They have also been successfully used to determine the role of particular genes as virulence and avirulence determinants in plant pathogens such as P. infestans (3) and Magnaporthe oryzae (87). Association studies could help uncover the genetic bases of traits such as pathogenicity, virulence, or fungicide resistance in $P$. capsici. Nevertheless, even weak population structure obscures the discovery of functionally important variation using association genetics. Because the clusters identified are somewhat structured, stratification of $P$. capsici by geography, host, and mefenoxam sensitivity will be important to control for in association analysis of phenotypic traits of interest. Studies investigating the genetic structure of $P$. capsici populations by host or by mefenoxam sensitivity nested within geography will be key to select appropriate individuals for association studies in $P$. capsici.

Bayesian clustering, split decomposition networks, and statistical parsimony genealogies allowed for the detection of non- $P$. capsici isolates in our sample. Isolates from cluster 10 corresponded to $P$. tropicalis and isolates from cluster 11 corresponded to isolates from Brazil (cacao) and Michigan (English Ivy) that were closely related to $P$. capsici and $P$. tropicalis but formed a distinct group in our analyses. Oudemans and Coffey used phylogenetic methods to separate $P$. tropicalis isolates (CAP2) from $P$. capsici SS (CAP1) (57). Several studies have detected the separation of $P$. capsici and $P$. tropicalis but no evidence of admixture between them was previously found $(10,53,57,88)$, because phylogenetic methods do not allow for the visualization of admixture. Clustering analysis in our study indicates that, even though $P$. tropicalis is found as a distinct cluster from $P$. capsici, some admixture has occurred between the species. The observed admixture could be due to ancestral polymorphism or recent recombination events, given that it is possible to obtain interspecific progeny in the lab (10); no hybrids have been characterized from nature. With more samples and several linked markers, it may be possible to detect introgression events or recent gene flow between the species and determine the existence of natural hybrids $(12,55,80)$.

Isolates from cluster 11 appear separated from $P$. capsici and $P$. tropicalis in the networks and genealogies and show no admixture in the structure analysis. The lack of admixture in cluster 11 could be due to the few isolates we have in that cluster (three from Brazil and cacao and one from Michigan and English Ivy). With more samples, it is possible that admixture will be detected revealing that cluster 11 corresponds to $P$. tropicalis or $P$. capsici. 
However, taking into consideration the genealogies and networks that support the separation of haplotypes in three distinct groups, it is also possible that cluster 11 corresponds to a distinct phylogenetic species. In their $P$. capsici study, Oudemans and Coffey also found a third distinct clade (CAP3) that contained isolates from Brazil and cacao (57) that likely correspond to cluster 11. Isolates from Brazil and cacao also formed a separate clade in other studies $(7,10)$. Detection of isolates from cluster 11 seems to be possible by combining information from several markers. In the study by Donahoo and Lamour, these isolates appear on the same clade with a few $P$. capsici isolates in an internal transcribed spacer-based phylogeny but separation of such isolates was observed in other phylogenies based on amplified fragment length polymorphisms and nuclear genes in the same study (10). This is not surprising because haplotypes of cluster 11 showed high similarity to $P$. capsici in some genes, whereas other genomic regions were more similar to $P$. tropicalis according to BLAST. Because the structure analysis uses multilocus genotypes and allelic frequencies for clustering, we believe that it constitutes a valuable tool that could complement phylogenetic studies by providing information about population membership and admixture to aid in the delimitation of phylogenetic species in highly recombining pathogens. However, to truly define whether there are genetic barriers to mating among $P$. capsici, $P$. tropicalis, and isolates in cluster 11, comparisons of a wide range of inter- and intracluster crosses between isolates from diverse origins is needed.

Isolates used in this study were obtained from colleagues around the world and from our $P$. capsici collection. Large numbers of isolates could not be obtained from several localities and most isolates come from common vegetable hosts. Isolates from tropical hosts were less represented, and no samples from wild hosts or weeds were obtained. Finding non- $P$. capsici isolates in our sample was unexpected; therefore, the number of isolates sampled for clusters 10 and 11 was low for a populationbased study. Sparse sampling is common in plant pathogen worldwide population studies. One example is work done by Goss et al. in $P$. ramorum populations (28). Nonetheless, Bayesian clustering can yield valuable information about the population structure of plant pathogen populations. The number and type of markers used can affect the analysis. Loci included in our study were highly informative, as indicated by polymorphism, recombination, and diversity analysis. Nuclear loci were more diverse than mitochondrial loci in this study, as has been previously observed for $P$. capsici and $P$. parasitica (15). We were able to detect clustering in our samples with the 10 genes used. Previous studies have shown that, for clustering to be robust, $<40$ markers and as few as 7 markers (63) can be used if they are highly informative, but using at least 50 markers is preferred (70). Obviously, structure can only be detected in the samples being analyzed. More clusters likely exist in $P$. capsici because apparent structure may be underestimated when using sparse sampling and few markers (70). Future studies with uniform global sampling and hundreds of markers could determine whether additional genetic clusters are present in $P$. capsici. The approach used in this study could be applied to other plant pathogens, where using a large number of markers is not feasible due to high costs or scarce genomic resources available, given that the markers used are highly informative. Although sequencing 10 genes is likely necessary to classify isolates into the clusters identified in our study, ideally, a high-throughput and cost-effective set of $>50$ markers should be developed to more robustly classify isolates while minimizing the costs associated with genotyping isolates.

$P$. capsici is a diverse and highly recombining species of economic importance. Our findings of genetic structuring in $P$. capsici populations, coupled with observations of differences in virulence of particular isolates when inoculated in diverse hosts $(16,21,65,66)$, highlights the importance of selecting isolates from diverse hosts and geographic origin for breeding programs. When developing diagnostic tools, fungicides, and resistant host cultivars, representative isolates from all genetic clusters should be used to account for global genetic diversity. This investigation of genetic structure of $P$. capsici populations may be used to guide isolate selection to improve efficacy of breeding programs. Continued genotyping of $P$. capsici will be necessary to track the diversification of inferred clusters and to identify new ones.

\section{ACKNOWLEDGMENTS}

We thank the many colleagues listed in Supplementary Table 1 for providing isolates for this research; all the members of the Hausbeck lab for their valuable suggestions and help; H. Gutting, H. Sweet, A. Lebeis, K. Heslip, R. Heslip, M. Wood, and J. Passmore for technical assistance; J. J. Morrice for providing the program PST to generate population structure figures; and D. R. Matute and J. Smith for critical reading of the manuscript.

\section{LITERATURE CITED}

1. Altschul, S. F., Gish, W., Miller, W., Myers, E. W., and Lipman, D. J. 1990. Basic local alignment search tool. J. Mol. Biol. 215:403-410.

2. Altschul, S. F., Madden, T. L., Schaffer, A. A., Zhang, J., Zhang, Z., Miller, W., and Lipman, D. J. 1997. Gapped BLAST and PSI-BLAST: a new generation of protein database search programs. Nucleic Acids Res. 25:3389-3402.

3. Armstrong, M. R., Whisson, S. C., Pritchard, L., Bos, J. I. B., Venter, E., Avrova, A. O., Rehmany, A. P., BÃhme, U., Brooks, K., Cherevach, I., Hamlin, N., White, B., Fraser, A., Lord, A., Quail, M. A., Churcher, C., Hall, N., Berriman, M., Huang, S., Kamoun, S., Beynon, J. L., and Birch, P. R. J. 2005. An ancestral oomycete locus contains late blight avirulence gene Avr3a, encoding a protein that is recognized in the host cytoplasm. PNAS 102:7766-7771.

4. Awadalla, P. 2002. The evolutionary genomics of pathogen recombination. Nat. Rev. Genet. 4:50-60.

5. Bergl, R. A., and Vigilant, L. 2007. Genetic analysis reveals population structure and recent migration within the highly fragmented range of the Cross River gorilla (Gorilla gorilla diehli). Mol. Ecol. 16:501-516.

6. Blair, J. E., Coffey, M. D., Park, S.-Y., Geiser, D. M., and Kang, S. 2008. A multi-locus phylogeny for Phytophthora utilizing markers derived from complete genome sequences. Fungal Genet. Biol. 45:266-277.

7. Bowers, J. H., Martin, F. N., Tooley, P. W., and Luz, E. D. M. N. 2007. Genetic and morphological diversity of temperate and tropical isolates of Phytophthora capsici. Phytopathology 97:492-503.

8. Clement, M., Posada, D., and Crandall, K. 2000. TCS: a computer program to estimate gene genealogies. Mol. Ecol. 9:1657-1660.

9. Davidson, J. M., Werres, S., Garbelotto, M., Hansen, E. M., and Rizzo, D. M. 2003. Sudden oak death and associated diseases caused by Phytophthora ramorum. Plant Health Progress doi: 10.1094/PHP-20030707-01-DG.

10. Donahoo, R. S., and Lamour, K. H. 2008. Interspecific hybridization and apomixis between Phytophthora capsici and Phytophthora tropicalis. Mycologia 100:911-920.

11. Erwin, D. C., and Ribeiro, O. K. 1996. Phytophthora Diseases Worldwide. American Phytopathological Society Press, St. Paul, MN.

12. Falush, D., Stephens, M., and Pritchard, J. K. 2007. Inference of population structure using multilocus genotype data: Dominant markers and null alleles. Mol. Ecol. Notes 7:574-578.

13. Falush, D., Wirth, T., Linz, B., Pritchard, J. K., Stephens, M., Kidd, M., Blaser, M. J., Graham, D. Y., Vacher, S., Perez-Perez, G. I., Yamaoka, Y., Megraud, F., Otto, K., Reichard, U., Katzowitsch, E., Wang, X., Achtman, M., and Suerbaum, S. 2003. Traces of human migrations in Helicobacter pylori populations. Science 299:1582-1585.

14. Fonseca, D. M., Keyghobadi, N., Malcolm, C. A., Mehmet, C., Schaffner, F., Mogi, M., Fleischer, R. C., and Wilkerson, R. C. 2004. Emerging vectors in the Culex pipiens complex. Science 303:1535-1538.

15. Forster, H., Oudemans, P., and Coffey, M. D. 1989. Mitochondrial and nuclear DNA diversity within six species of Phytophthora. Exp. Mycol. 14:18-31.

16. Foster, J. M., and Hausbeck, M. K. 2010. Resistance of pepper to Phytophthora crown, root, and fruit rot is affected by isolate virulence. Plant Dis. 94:24-30.

17. Francois, O., Blum, M. G. B., Jakobsson, M., and Rosenberg, N. A. 2008. Demographic history of European populations of Arabidopsis thaliana. PLoS Genet. 4:e10000075.

18. French-Monar, R. D., Jones, J. B., and Roberts, P. D. 2006. Charac- 
terization of Phytophthora capsici associated with roots of weeds on Florida vegetable farms. Plant Dis. 90:345-350.

19. Fu, Y. X., and Li, W. H. 1993. Statistical tests of neutrality of mutations. Genetics 133:693-709.

20. Garcia-Barcelo, M.-M., Tang, C. S.-m., Ngan, E. S.-w., Lui, V. C.-h., Chen, Y., So, M.-t., Leon, T. Y.-y., Miao, X.-p., Shum, C. K.-y., Liu, F.-q., Yeung, M.-y., Yuan, Z.-w., Guo, W.-h., Liu, L., Sun, X.-b., Huang, L.-m., Tou, J.-f., Song, Y.-q., Chan, D., Cheung, K. M. C., Wong, K. K.-y., Cherny, S. S., Sham, P.-c., and Tam, P. K.-h. 2009. Genome-wide association study identifies NRG1 as a susceptibility locus for Hirschsprung's disease. PNAS 106:2694-2699.

21. Gevens, A. J., Ando, K., Lamour, K. H., Grumet, R., and Hausbeck, M. K. 2006. A detached cucumber fruit method to screen for resistance to Phytophthora capsici and effect of fruit age on susceptibility to infection. Plant Dis. 90:1276-1282.

22. Gevens, A. J., Donahoo, R. S., Lamour, K. H., and Hausbeck, M. K. 2007. Characterization of Phytophthora capsici from Michigan surface irrigation water. Phytopathology 97:421-428.

23. Gevens, A. J., Donahoo, R. S., Lamour, K., and Hausbeck, M. K. 2008. Characterization of Phytophthora capsici causing foliar and pod blight of snap beans in Michigan. Plant Dis. 92:201-209.

24. Gobena, D. J., Roig, J., Hulvey, J., and Lamour, K. 2010. Genetic diversity of the vegetable pathogen Phytophthora capsici in Argentina. (Abstr.) Phytopathology 100:S41.

25. Gomez-Alpizar, L., Carbone, I., and Ristaino, J. B. 2007. An Andean origin of Phytophthora infestans inferred from mitochondrial and nuclear gene genealogies. PNAS 104:3306-3311.

26. Goodwin, S. B. 1997. The population genetics of Phytophthora. Phytopathology 87:462-473.

27. Goodwin, S. B., Cohen, B. A., and Fry, W. E. 1994. Panglobal distribution of a single clonal lineage of the Irish potato famine fungus. PNAS 91:11591-11595.

28. Goss, E. M., Larsen, M., Chastagner, G. A., Givens, D. R., and Grunwald, N. J. 2009. Population genetic analysis infers migration pathways of Phytophthora ramorum in US nurseries. PLoS Pathogens 5:e10000583.

29. Granke, L. L., Windstam, S. T., Hoch, H. C., Smart, C. D., and Hausbeck, M. K. 2009. Dispersal and movement mechanisms of Phytophthora capsici sporangia. Phytopathology 99:1258-1264.

30. Hahn, R., and Werres, S. 1997. Development of a dot immunobinding assay to detect Phytophthora spp. in naturally dark-rooted woody plants. Ann. Appl. Biol. 130:453-466.

31. Hartl, D. L., and Clark, A. G. 1997. Principles of Population Genetics. Sinauer Associates, Inc., Sunderland, MA

32. Hausbeck, M. K., and Lamour, K. H. 2004. Phytophthora capsici on vegetable crops: research progress and management challenges. Plant Dis. 88:1292-1303.

33. Huang, X., Wei, X., Sang, T., Zhao, Q., Feng, Q., Zhao, Y., Li, C., Zhu, C., Lu, T., Zhang, Z., Li, M., Fan, D., Guo, Y., Wang, A., Wang, L., Deng, L., Li, W., Lu, Y., Weng, Q., Liu, K., Huang, T., Zhou, T., Jing, Y., Li, W., Lin, Z., Buckler, E. S., Qian, Q., Zhang, Q.-F., Li, J., and Han, B. 2010. Genome-wide association studies of 14 agronomic traits in rice landraces. Nat. Genet. 42:961-967.

34. Hudson, R. R. 1987. Estimating the recombination parameter of a finite population model without selection. Genet. Res. 50:245-250.

35. Hudson, R. R., and Kaplan, N. L. 1985. Statistical properties of the number of recombination events in the history of a sample of DNA sequences. Genetics 111:147-164.

36. Hurtado-Gonzáles, O., Aragon-Caballero, L., Apaza-Tapia, W., Donahoo, R., and Lamour, K. 2008. Survival and spread of Phytophthora capsici in coastal Peru. Phytopathology 98:688-694.

37. Huson, D. H., and Bryant, D. 2006. Application of phylogenetic networks in evolutionary studies. Mol. Biol. Evol. 23:254-267.

38. Hwang, B. K., Arthur, W. A., and Heitefuss, R. 1991. Restriction fragment length polymorphisms of mitochondrial DNA among Phytophthora capsici isolates from pepper (Capsicum annuиm). Syst. Appl. Microbiol. 14:111-116.

39. Jackson, K., Yin, J., Csinos, A., Scherm, H., and Ji, P. 2010. Diversity of Phytophthora capsici from vegetable crops in Georgia. (Abstr.) Phytopathology 100:S55.

40. Keller, S. R., Olson, M. S., Silim, S., Schroeder, W., and Tiffin, P. 2010. Genomic diversity, population structure, and migration following rapid range expansion in the Balsam Poplar, Populus balsamifera. Mol. Ecol. 19:1212-1226.

41. Lamour, K. 2009. Phytophthora capsici: Sex, Selection, and the Wealth of Variation. John Wiley \& Sons, Inc., New York.

42. Lamour, K. H., and Hausbeck, M. K. 2000. Mefenoxam insensitivity and the sexual stage of Phytophthora capsici in Michigan cucurbit fields. Phytopathology 90:396-400.

43. Lamour, K. H., and Hausbeck, M. K. 2001. The dynamics of mefenoxam insensitivity in a recombining population of Phytophthora capsici characterized with amplified fragment length polymorphism markers. Phytopathology 91:553-557.

44. Lamour, K. H., and Hausbeck, M. K. 2001. Investigating the spatiotemporal genetic structure of Phytophthora capsici in Michigan. Phytopathology 91:973-980.

45. Lamour, K. H., and Hausbeck, M. K. 2003. Effect of crop rotation on the survival of Phytophthora capsici in Michigan. Plant Dis. 87:841-845.

46. Lamour, K. H., and Hausbeck, M. K. 2003. Susceptibility of mefenoxamtreated cucurbits to isolates of Phytophthora capsici sensitive and insensitive to mefenoxam. Plant Dis. 87:920-922.

47. Lee, B. K., Kim, B. S., Chang, S. W., and Hwang, B. K. 2001. Aggressiveness to pumpkin cultivars of isolates of Phytophthora capsici from pumpkin and pepper. Plant Dis. 85:497-500.

48. Leonian, L. H. 1922. Stem and fruit blight of chilies caused by Phytophthora capsici $\mathrm{sp}$. Phytopathology 12:401-408.

49. Librado, P., and Rozas, J. 2009. DnaSP v5: A software for comprehensive analysis of DNA polymorphism data. Bioinformatics 25:1451-1452.

50. Luz, E. D. M. N., Cerqueira, A. O., Faleiro, F. G., Dantas Neto, A., Matsuoka, K., and Marques, J. R. B. 2003. Diversidade genetica de isolados de Phytophthora capsici de diferentes hospedeiros com base em marcadores RAPD patogenicidade e morfologia. Fitopatol. Bras. 28:559564.

51. Maddison, W. P., and Maddison, D. R. 2002. MacClade: Analysis of Phylogeny and Character Evolution. 4.06 OSX. Sinauer Associates, Sunderland, MA.

52. Maniatis, T., Fritsch, E. F., and Sambrook, J. 1982. Molecular Cloning: A Laboratory Manual. Cold Spring Harbor Laboratory, Cold Spring Harbor, NY.

53. Mchau, G. R. A., and Coffey, M. D. 1995. Evidence for the existence of two subpopulations in Phytophthora capsici and a redescription of the species. Mycol. Res. 99:89-102.

54. Nei, M. 1987. Molecular Evolutionary Genetics. Columbia University Press, New York.

55. Nielsen, E. E., Hansen, M. M., Ruzzante, D. E., Meldrup, D., and Grønkjær, P. 2003. Evidence of a hybrid-zone in Atlantic cod (Gadus morhua) in the Baltic and the Danish Belt Sea revealed by individual admixture analysis. Mol. Ecol. 12:1497-1508.

56. Oelke, L. M., and Bosland, P. W. 2003. Differentiation of race specific resistance to Phytophthora root rot and foliar blight in Capsicum аппиит. J. Am. Soc. Hortic. Sci. 128:213-218.

57. Oudemans, P., and Coffey, M. D. 1991. A revised systematics of twelve papillate Phytophthora species based on isozyme analysis. Mycol. Res. 95:1025-1046.

58. Park, J., Park, B., Veeraraghavan, N., Jung, K., Lee, Y.-H., Blair, J. E., Geiser, D. M., Isard, S., Mansfield, M. A., Nikolaeva, E., Park, S.-Y., Russo, J., Kim, S., H., Greene, M., Ivors, K. L., Balci, Y., Peiman, M., Erwin, D. C., Coffey, M. D., Rossman, A., Farr, D., Cline, E., Grunwald, N. J., Luster, D. G., Schrandt, J., Martin, F., Ribeiro, O. K., Makalowska, I., and Kang, S. 2008. Phytophthora database: A forensic database supporting the identification and monitoring of Phytophthora. Plant Dis. 92:966-972.

59. Parra, G., and Ristaino, J. B. 2001. Resistance to mefenoxam and metalaxyl among field isolates of Phytophthora capsici causing Phytophthora blight of bell pepper. Plant Dis. 85:1069-1075.

60. Pennisi, A. M., Agosteo, G. E., Cacciola, S. O., Pane, A., and Faedda, R. 1998. Insensitivity to metalaxyl among isolates of Phytophthora capsici causing root rot and crown rot of pepper in Southern Italy. Plant Dis. 82:1283

61. Polach, F. J., and Webster, R. K. 1972. Identification of strains and inheritance of pathogenicity in Phytophthora capsici. Phytopathology 62:20-26.

62. Posada, D., and Crandall, K. A. 2001. Intraspecific gene genealogies: trees grafting into networks. Trends Ecol. Evol. 16:37-45.

63. Pritchard, J. K., Stephens, M., and Donnelly, P. 2000. Inference of population structure using multilocus genotypic data. Genetics 155:945959.

64. Prospero, S., Hansen, E. M., Grunwald, N. J., and Winton, L. M. 2007. Population dynamics of the sudden oak death pathogen Phytophthora ramorum in Oregon from 2001 to 2004. Mol. Ecol. 16:2958-2973.

65. Quesada-Ocampo, L. M., Fulbright, D. W., and Hausbeck, M. K. 2009. Susceptibility of Fraser fir to Phytophthora capsici. Plant Dis. 93:135141.

66. Quesada-Ocampo, L. M., and Hausbeck, M. K. 2010. Resistance in tomato and wild relatives to crown and root rot caused by Phytophthora capsici. Phytopathology 100:619-627.

67. R-Development-Core-Team. 2008. R: A Language and Environment for Statistical Computing. R Foundation for Statistical Computing, Vienna.

68. Ristaino, J. B. 1990. Intraspecific variation among isolates of Phytophthora capsici from pepper and cucurbit fields in North Carolina. Phytopathology 80:1253-1259. 
69. Ristaino, J. B., and Johnston, S. A. 1999. Ecologically based approaches to management of Phytophthora blight on bell pepper. Plant Dis. 83:10801089.

70. Rosenberg, N. A., Mahajan, S., Ramachandran, S., Zhao, C., Pritchard, J. K., and Feldman, M. W. 2005. Clines, clusters, and the effect of study design on the inference of human population structure. PLoS Genet. $1: \mathrm{e} 70$.

71. Rosenberg, N. A., Pritchard, J. K., Weber, J. L., Cann, H. M., Kidd, K. K., Zhivotovsky, L. A., and Feldman, M. W. 2002. The genetic structure of human populations. Science 298:2381-2385.

72. Rozen, S., and Skaletsky, H. J. 2000. Primer3 on the WWW for General Users and for Biologist Programmers. Humana Press, Totowa, NJ.

73. Silvar, C., Merino, F., and Díaz, J. 2006. Diversity of Phytophthora capsici in Northwest Spain: analysis of virulence, metalaxyl response, and molecular characterization. Plant Dis. 90:1135-1142.

74. Stephens, M., Smith, N. J., and Donnelly, P. 2001. A new statistical method for haplotype reconstruction from population data. Am. J. Hum. Genet. 68:978-989.

75. Stumpf, M. P. H., and McVean, G. A. T. 2003. Estimating recombination rates from population-genetic data. Nat. Rev. Genet. 4:959-967.

76. Tajima, F. 1983. Evolutionary relationship of DNA sequences in finite populations. Genetics 105:437-460.

77. Tajima, F. 1989. Statistical method for testing the neutral mutation hypothesis by DNA Polymorphism. Genetics 123:585-595.

78. Tatarenkov, A., Gao, H., Mackiewicz, M., Taylor, D. S., Turner, B. J., and Avise, J. C. 2007. Strong population structure despite evidence of recent migration in a selfing hermaphroditic vertebrate, the mangrove killifish (Kryptolebias marmoratus). Mol. Ecol. 16:2701-2711.

79. Tian, D., and Babadoost, M. 2003. Genetic variation among isolates of
Phytophthora capsici from Illinois. (Abstr.) Phytopathology 93:S84.

80. Vähä, J.-P., and Primmer, C. R. 2006. Efficiency of model-based Bayesian methods for detecting hybrid individuals under different hybridization scenarios and with different numbers of loci. Mol. Ecol. 15:63-72.

81. Walker, S. J., and Bosland, P. W. 1999. Inheritance of Phytophthora root rot and foliar blight resistance in pepper. J. Am. Soc. Hortic. Sci. 124:1418.

82. Wang, Z., Langston, D. B., Csinos, A. S., Gitaitis, R. D., Walcott, R. R., and $\mathrm{Ji}$, P. 2009. Development of an improved isolation approach and simple sequence repeat markers to characterize Phytophthora capsici populations in irrigation ponds in southern Georgia. Appl. Environ. Microbiol. 75:5467-5473.

83. Waterhouse, G. M. 1963. Key to the Species of Phytophthora de Bary. Commonwealth Mycological Society, Kew, Surrey, UK.

84. Watterson, G. A. 1975. On the number of segregating sites in genetical models without recombination. Theor. Popul. Biol. 7:256-276.

85. Weber, G. F. 1932. Blight of peppers in Florida caused by Phytophthora capsici. Phytopathology 22:775-780.

86. Wilson, D. J., Falush, D., and McVean, G. 2005. Germs, genomes and genealogies. Trends Ecol. Evol. 20:39-45.

87. Yoshida, K., Saitoh, H., Fujisawa, S., Kanzaki, H., Matsumura, H., Yoshida, K., Tosa, Y., Chuma, I., Takano, Y., Win, J., Kamoun, S., and Terauchi, R. 2009. Association genetics reveals three novel avirulence genes from the rice blast fungal pathogen Magnaporthe oryzae. Plant Cell 21:1573-1591.

88. Zhang, Z. G., Zhang, J. Y., Zheng, X. B., Yang, Y. W., and Ko, W. H. 2004. Molecular distinctions between Phytophthora capsici and Ph. tropicalis based on ITS sequences of ribosomal DNA. J. Phytopathol. 152:358-364. 